\title{
A Mechanisms-Based Approach to Detecting Recent Anthropogenic Hydroclimate Change*
}

\author{
RichARD SEAGER AND NAOMI NAIK \\ Lamont-Doherty Earth Observatory, Columbia University, Palisades, New York
}

(Manuscript received 24 January 2011, in final form 24 May 2011)

\begin{abstract}
Both naturally occurring La Niña events and model-projected anthropogenic-driven global warming are associated with widespread drying in the subtropics to midlatitudes. Models suggest anthropogenic drying should already be underway but climate variability on interannual to multidecadal time scales can easily obscure any emerging trend, making it hard to assess the validity of the simulated forced change. Here, the authors address this problem by using model simulations and the twentieth-century reanalysis to distinguish between natural variability of, and radiatively forced change in, hydroclimate on the basis of the mechanisms of variations in the three-dimensional moisture budget that drive variations in precipitation minus evaporation $(P-E)$. Natural variability of $P-E$ is dominated by the El Niño-Southern Oscillation (ENSO) cycle and is "dynamics dominated" in that the associated global $P-E$ anomalies are primarily driven by changes in circulation. This is quite well reproduced in the multimodel mean of 15 models used in the Intergovernmental Panel on Climate Change Fourth Assessment Report (IPCC AR4)/Coupled Model Intercomparison Project 3 (CMIP3). In contrast, radiatively forced $P-E$ change is "thermodynamics mediated" in that the rise in specific humidity leads to intensified patterns of moisture transport and $P-E$. But, as for ENSO, the poleward shift of the storm tracks and mean meridional circulation cells also contribute to changes in $P-E$. However, La Niña and radiatively forced changes in the zonal mean flow are distinct in the tropics. These distinctions are applied to the post-1979 record of $P-E$ in the twentieth-century reanalysis. ENSO-related variations strongly influence the observed $P-E$ trend since 1979, but removal of this influence leaves an emerging pattern of $P-E$ change consistent with the predictions of the IPCC AR4/CMIP3 models over this period together with, to some extent, consistent contributions from dynamical and thermodynamical mechanisms and consistent changes in the zonal mean circulation. The forced trends are currently weak compared to those caused by internal variability.
\end{abstract}

\section{Introduction}

Atmospheric modeling has made clear that the great, multiyear, droughts that have afflicted the American West in historical times were all forced, wholly or in part, by small, equally persistent La Niña-like sea surface temperature (SST) anomalies in the tropical Pacific (Schubert et al. 2004b,a; Seager et al. 2005b; Herweijer et al. 2006; Seager 2007; Seager et al. 2008, 2009). These droughts include the Dust Bowl drought of the 1930s, the 1950s

\footnotetext{
* Lamont-Doherty Earth Observatory Contribution Number 7498.
}

Corresponding author address: Richard Seager, Lamont Doherty Earth Observatory, Columbia University, 61 Route 9W, Palisades, NY 10964.

E-mail: seager@ldeo.columbia.edu
Southwest drought, three in the mid-to-late nineteenth century and the post-1998 "turn-of-the-century" drought. Warm subtropical North Atlantic SSTs anomalies appear to have also played a role in the 1930s and 1950s droughts (Schubert et al. 2004b; Seager et al. 2008). For the case of the Dust Bowl, Hoerling et al. (2009) have argued for an additional role of internal atmosphere variability while Cook et al. $(2008,2009,2011)$ have argued that the dust storms intensified the drought and moved its center northward.

Model simulations suggest that the mechanisms for the droughts are essentially lower frequency versions of the dynamics operating during the El Niño-Southern Oscillation (ENSO) cycle. The circumglobal tropical tropospheric cooling caused by cold tropical Pacific SSTs and the anomalous heat uptake by the ocean weakens the subtropical jet stream on its equatorward side. This prevents transient eddies from penetrating as far equatorward 
as in normal or El Niño winters creating an anomalous pattern of transient eddy momentum flux convergence that drives midlatitude descent, low-level mean flow moisture divergence, and reduced precipitation (Seager et al. 2003, 2005a; Seager 2007; Lu et al. 2008). This general subtropical to midlatitude drying can be accentuated over southern North America during La Niñas by the descending motion in the tropically forced Rossby wave train. Further, the Rossby wave interacts with the North Pacific storm track (Trenberth et al. 1988) to create a northward-shifted path for Pacific storms that can dry southwest North America (SWNA). It has been argued that the shift arises from linear wave refraction (Seager et al. 2010a; Harnik et al. 2011).

The subtropical dry zones in general are robustly projected to dry as a consequence of global warming induced by rising greenhouse gases (GHGs; Held and Soden 2006, hereafter HS). This drying includes SWNA but is particularly strong in the Mediterranean region (Seager et al. 2007). Models also project that the subtropical dry zones will expand poleward. This subtropical drying and expansion is related to the poleward expansion of the Hadley Cell and poleward shift of the midlatitude storm tracks that occurs in response to global warming (Yin 2005; Lu et al. 2007, 2008; Previdi and Liepert 2007). As such, for both La Niña-induced natural droughts and anthropogenic climate change, drying at the subtropicalextratropical margins is associated with a poleward expanded Hadley Cell and poleward displaced storm track. But there the similarity ends. During La Niña-induced extratropical droughts precipitation is suppressed over the tropical Pacific Ocean and the tropical troposphere cools. During anthropogenic drying and expansion of the subtropics the multimodel mean of climate change projections show an increase of precipitation over the tropical Pacific and there is a meridionally broad warming of the tropical troposphere.

Consequently, similar responses of extratropical circulation, and associated hydrology, to La Niña and global warming must come about from quite different causes. Lu et al. (2008) have suggested possible explanations for this. In their assessment the explanation for the La Niña anomalies is as in Seager et al. (2003) (see also Seager et al. 2010a; Harnik et al. 2011) and involves the influence of tropical heating-forced mean flow anomalies on transient eddy propagation. In contrast, under global warming transient eddies either 1) do not propagate as deeply into the tropics because of an increase in their phase speed and, hence, a poleward shift of the subtropical critical line or 2) a meridionally broad upper-tropospheric warming and increase in static stability centered around the equator stabilizes the subtropics to baroclinic instability shifting the latitude of eddy generation poleward.
However, the meridionally broad upper-tropospheric warming under global warming, much wider than the Rossby radius-limited meridional scale of El Niño-forced warming, has been attributed to an increase in subsidence forced by transient eddy momentum flux convergence and, hence, is not causal of the storm track shift ( $\mathrm{Wu}$ et al. 2010, 2012). Regardless, the work of Lu et al. (2008) provides some guidance for why both La Niña and global warming can cause extratropical drying even though the circulation and thermodynamic structure in the tropics with which they are associated are quite different (even opposite).

But there are other differences between La Niña- and global warming-induced precipitation anomalies. Precipitation anomalies forced by La Niña are "dynamics dominated" in that they are, to first order, caused by circulation anomalies acting on the mean humidity and only to a lesser extent influenced by humidity anomalies (Huang et al. 2005; Seager 2007), This is not the case for precipitation anomalies forced by rising GHGs and global warming. In a detailed breakdown of the changes in the moisture budget forced by global warming, Seager et al. (2010b, hereafter SNV) showed that an increase in specific humidity, according to an assumed fixed relative humidity, in combination with an unchanged circulation accounts for a sizable share of the model-projected change in precipitation minus evaporation, $P-E$ (as pointed out by HS). Rising specific humidity amplifies the pattern of moisture divergence and convergence by the mean flow making wet areas wetter and dry areas drier. This has also been referred to as the "rich get richer" mechanism (Chou and Neelin 2004; Chou et al. 2009). Further, for a given change in temperature at a given, fixed, relative humidity, the specific humidity will increase more in warm areas than cooler areas because of the nonlinearity in the ClausiusClapeyron relation allowing an increase in poleward transient eddy moisture fluxes further contributing to the drying of the subtropics and moistening at higher latitudes. However, the global warming change in $P-E$ is "thermodynamics mediated" not "thermodynamics dominated" because, as also shown, dynamical changes including the poleward expansion of the Hadley Cell, the poleward shift of the storm tracks, and the slowdown of the tropical overturning circulation also significantly contribute to changes in $P-E$.

According to simulations and projections of radiatively forced climate change anthropogenic drying of the subtropics should have begun late in the last century (Seager et al. 2007; Mariotto et al. 2009). Many researchers have claimed to identify an expansion in recent decades of the tropics and poleward shift of the jet stream (e.g., Seidel et al. 2008; Archer and Caldeira 2008; Lu et al. 2009) and to have detected the expected climate change 
signal in precipitation trends (Neelin et al. 2006; Zhang et al. 2008). However, none of this is unambiguously clear because of changes in observing systems and because natural variability on seasonal to multidecadal time scales can easily obscure any incipient anthropogenic drying (Hoerling et al. 2010). For example, it is possible that the $1997 / 98$ El Niño heralded an internally generated shift toward the state of Pacific decadal variability (PDV; Zhang et al. 1997) in which the tropical Pacific is cooler and, hence, SWNA is drier (Huang et al. 2005). However, recent analyses of 1950-2008 trends in sea surface salinity clearly show an enhancement of salinity contrasts consistent with an enhancement of $P-E$ contrasts (Durack and Wijffelsl 2010).

Whether model projections of a transition to increased aridity are correct and, if correct, already happening or imminent is of vital importance to water resource managers and others whose plans are dependent on water availability. Here, we adopt a new method to detect and attribute hydroclimate variations to natural and radiatively forced causes by conducting an integrated analysis of the atmospheric moisture budget and related circulation. The work will use the 15 models from Climate Model Intercomparison Project 3 [(CMIP3), which were assessed by the Intergovernmental Panel on Climate Change Fourth Assessment Report (IPCC AR4)], making all the necessary moisture budget data available. Atmosphere reanalyses contain artificial trends in precipitation introduced by changes in satellite observing systems. Consequently, to examine forced change we turn to SST-forced GCM simulations and the SST-forced, surface pressure-assimilating twentieth-century reanalysis of Compo et al. (2011). Using these data we will

- contrast the dynamical and thermodynamical mechanisms that drive natural $P-E$ variability and radiatively forced $P-E$ change within the models used by IPCC AR4;

- compare the internal moisture budget variability within the models used by AR4 with the observed internal variability as represented within the twentieth-century reanalysis; and

- for the post-1979 period using SST-forced simulations and the SST-forced, surface pressure-assimilating reanalysis, identify patterns of internal variability of the moisture budget and remove these to examine the residual for evidence of the mechanisms of forced change.

It is expected that analysis of the multivariate moisture budget will yield more robust conclusions than analyses of precipitation or circulation alone. As will be shown, even with this more inclusive methodology, attempts to identify anthropogenic hydroclimate trends over recent decades lead to only tentative conclusions because the natural variability of $P-E$ on seasonal to multidecadal time scales is currently so large compared with the model-projected emerging $P-E$ trends. However, we will argue that, amidst substantial caveats, available atmosphere model and observational-based evidence is supportive of coupled atmosphere-ocean model projections of $P-E$ change.

\section{Models, data, and methods}

To evaluate model moisture budgets requires daily data for winds, humidity, and surface pressure on an adequate number of vertical levels. Only 15 of the models participating in IPCC AR4/CMIP3 (Meehl et al. 2007) make all this data available. The daily data are also only available for limited periods-1960-2000 for the twentiethcentury simulations and 2046-65 for the twenty-first century projections. Here, we analyze the Special Report on Emissions Scenario (SRES) A1B "middle-ofthe-road" emissions scenario in which emissions drop after midcentury and $\mathrm{CO}_{2}$ continues to climb to $720 \mathrm{ppm}$ by end of century. Details of the analysis of model fields are given in SNV but, essentially, all analyses are performed on the model native horizontal grid and standard pressure levels before a multimodel ensemble mean is performed. No attempt is made to use the same numerical methods as used in the models themselves. All spatial derivatives are computed with centered, second-order, differencing and first-order one-sided differencing adjacent to undefined, below land surface, values. The vertical integrals are performed assuming a piecewise linear profile from the surface pressure to the top level and integrating exactly for a second-order approximation. This leaves a nonnegligible residual due to the approximations involved and the neglect of moisture diffusion in the models. See Table 1 for more details on the models used. To determine the model-projected, radiatively forced, change in the moisture budget we use the difference between 2046-65 with the SRES A1B scenario and 19602000 from the twentieth-century simulations. To determine the modeled natural variability in the moisture budget we examine only the twentieth-century simulations.

For observational data we originally intended to use the National Aeronautics and Space Administration's Modern Era Retrospective-Analysis for Research and Applications (MERRA) which has been designed for high quality representation of the hydrological cycle and covers 1979 to now (http://gmao.gsfc.nasa.gov/research/ merra/intro.php). However, due to the introduction of new satellites in 1998 and 2000, there is a notable jump in the precipitation with an increase in the global mean and more accentuated precipitation contrasts in the later periods. This prevents use of the MERRA reanalysis for 
TABLE 1. Models used in this study, their country of origin, the horizontal resolution of the atmosphere component, and the run used in the analysis. References to these models can be found in Vecchi and Soden (2007).

\begin{tabular}{|c|c|c|c|}
\hline Model name & Country & $\begin{array}{l}\text { Atmospheric } \\
\text { horizontal resolution }\end{array}$ & $\begin{array}{l}\text { Run number } \\
1961-2000 / 2046-65\end{array}$ \\
\hline $\begin{array}{l}\text { Coupled General Circulation Model, version } 3.1 \\
\text { (CGCM3.1) T47 }\end{array}$ & Canada & $\mathrm{T} 47$ & run1/run1 \\
\hline CGCM3.1 T63 & Canada & T63 & run1/run1 \\
\hline $\begin{array}{l}\text { Centre National de Recherches Météorologiques } \\
\text { Coupled Global Climate Model, version } 3 \\
\text { (CNRM-CM3) }\end{array}$ & France & T63 & run1/run1 \\
\hline $\begin{array}{l}\text { Commonwealth Scientific and Industrial Research } \\
\text { Organisation Mark version 3.0 (CSIRO Mk3.5) }\end{array}$ & Australia & T63 & run1/run1 \\
\hline GFLD CM2.0 & United States & $2.5^{\circ} \times 2^{\circ}$ & run1/run1 \\
\hline GFLD CM2.1 & United States & $2.5^{\circ} \times 2^{\circ}$ & run2/run1 \\
\hline $\begin{array}{l}\text { Goddard Institute for Space Studies Atmosphere-Ocean } \\
\text { Model (GISS-AOM) }\end{array}$ & United States & $4^{\circ} \times 3^{\circ}(\mathrm{C}$ grid $)$ & run1/run1 \\
\hline GISS Model E-R (GISS-ER) & United States & $5^{\circ} \times 4^{\circ}(\mathrm{B}$ grid $)$ & run1/run1 \\
\hline $\begin{array}{l}\text { Institute of Atmospheric Physics Flexible Global } \\
\text { Ocean-Atmosphere-Land System Model } \\
\text { (IAP FGOALS) }\end{array}$ & China & $\mathrm{T} 42$ & run1/run2 \\
\hline $\begin{array}{l}\text { Institute of Numerical Mathematics Coupled Model, } \\
\text { version 3.0 (INM-CM3.0) }\end{array}$ & Russia & $5^{\circ} \times 4^{\circ}$ & run1/run1 \\
\hline $\begin{array}{l}\text { L'Institut Pierre-Simon Laplace Coupled Model, version 4A } \\
\text { (IPSL CM4A) }\end{array}$ & France & $2.5^{\circ} \times 3.75^{\circ}$ & run1/run1 \\
\hline $\begin{array}{l}\text { Meteorological Institute of the University of Bonn, } \\
\text { ECHO-G Model (MIUBECHOG) }\end{array}$ & Germany/Korea & $\mathrm{T} 30$ & run $1 * /$ run1 \\
\hline $\begin{array}{l}\text { Model for Interdisciplinary Research on Climate 3.2, } \\
\text { medium-resolution version [MIROC3.2(medres)] }\end{array}$ & Japan & $\mathrm{T} 42$ & run1/run1 \\
\hline Max Planck Institute (MPI) ECHAM5 & Germany & T63 & run1/run2 \\
\hline MRI CGCM2.3 & Japan & $\mathrm{T} 42$ & run1/run1 \\
\hline
\end{tabular}

* Bad humidity data on day 256 of 1986 were replaced by interpolated data from adjacent days.

examining post-1979 trends and confounds efforts to examine internal variability. Other reanalyses, such as that of the National Centers for Environmental Prediction (NCEP)-National Center for Atmospheric Research (NCAR), can also be influenced by changes in observing systems. Precipitation date from rain gauges and satellites is an alternative but gauge data is nonexistent over the oceans, and of varying quality and density over land over recent decades, and the satellite data is also subject to changes in observing system.

In such a situation we are forced to make some difficult choices. First of all, to examine "observed" internal variability, to look at the trends and to determine the relative roles of internal variability and forced change in the history of $P-E$ we examine the post-1979 period. This period is chosen because it conforms to the satellite period of observations that has been used by others [see review by Seidel et al. (2008)]. Instead of using reanalyses for this work we use as our stand-ins for the observed record of $P-E$ and the moisture budget one surface pressureassimilating reanalysis and one SST-forced model, namely the following:

(i) The recently released twentieth-century reanalysis (Compo et al. 2011, http://www.esrl.noaa.gov/psd/ data/gridded/reanalysis/). This uses the 2008 experimental version of the NCEP Global Forecast System (GFS) model and is SST forced and assimilates only surface pressure data. This version of the GFS model was used because it has not only a scheme with parameterized $\mathrm{O}_{3}$ production and destruction (Saha et al. 2010) but also allows a specified past history of $\mathrm{CO}_{2}$ concentrations, volcanic aerosols, and incoming solar radiation. It was run at $\mathrm{T} 62$ resolution with 28 vertical levels. This is called 20CR hereafter.

(ii) A 16-member ensemble of simulations with the NCAR Community Climate Model 3 (CCM3) forced by observed SSTs [from Kaplan et al. (1998) in the tropical Pacific; Rayner et al. (2003); elsewhere, see Seager et al. (2005b) for more details]. All other boundary conditions (including trace gas content) are held fixed. This ensemble extends to March 2010 and is referred to as Global Ocean-Global Atmosphere (GOGA).

These two products have the advantage of providing consistent atmospheric states free of changes in the observing systems other than changes in data density and are better suited to analysis of trends than are the other reanalyses. However it must be noted that the $20 \mathrm{CR}$ 
does not assimilate upper-air data or any hydrological variables and, hence, its hydrological cycle is highly influenced by the model used and will likely suffer in realism as a result of flaws in the convection and other parameterization schemes in the model. The assimilation of surface pressure data means that the $20 \mathrm{CR}$ is not another SST-forced model dataset but the 20CR should not be thought of as an observational dataset either. However it is considered the most appropriate currently available estimate of the atmospheric state for the task at hand ere.

In both 20CR and some of the IPCC AR4/CMIP3 models variations in $\mathrm{O}_{3}$ occur. Hence the anthropogenic change examined here is not just driven by rising greenhouse gases. Indeed, $\mathrm{O}_{3}$ changes probably accounted for a substantial portion of Southern Hemisphere circulation and precipitation change over this period (Polvani et al. 2011; Kang et al. 2011).

The moisture budget equation that we will analyze is

$$
\begin{aligned}
\rho_{w} g(\bar{P}-\bar{E}) \approx & -\int_{0}^{\bar{p}_{s}}\left[\nabla \cdot(\overline{\overline{\mathbf{u}}} \overline{\bar{q}}+\overline{\overline{\mathbf{u}}} \hat{q}+\hat{\mathbf{u}} \overline{\bar{q}})+\nabla \cdot\left(\overline{\overline{\mathbf{u}}^{\prime} q^{\prime}}\right)\right] d p \\
& -\overline{q_{s} \mathbf{u}_{s} \cdot \nabla p_{s}} .
\end{aligned}
$$

In this the climatological monthly means are indicated by double overbars, monthly means by single overbars, the monthly departures from climatological monthly means by hats, and departures from monthly means by primes and total fields have neither primes nor overbars (e.g., $\mathbf{u}=\overline{\mathbf{u}}+\mathbf{u}^{\prime}=\overline{\overline{\mathbf{u}}}+\hat{\mathbf{u}}+\mathbf{u}^{\prime}$ ). In the text the unmodified $P-E$ is used in a general sense when its meaning is clear from the context. Here, $\rho_{w}$ is water density, $g$ is the acceleration due to gravity, $p$ is pressure, $\mathbf{u}$ is the horizontal vector wind, $q$ is specific humidity, and subscript $s$ indicates surface values. The first term on the right-hand side describes moisture convergence by the mean flow and the second term moisture convergence by the transient flow. The final term cannot be evaluated for all models since many did not save daily surface values of winds and specific humidity. We evaluated it for the Geophysical Fluid Dynamics Laboratory Climate Model version 2.1 (GFDL CM2.1) using daily data and found that it could be reasonably approximated using monthly data. We then computed it for all 15 models using monthly data and found it to provide a uniform positive $P-E$ tendency (because of flow down the pressure gradient). However, this term is several times smaller than the other terms and we will discuss it no more. The term involving the covariance between monthly mean departures from climatology has been dropped but was found to be small.

Following SNV (albeit with somewhat different notation), we next divide changes, denoted by $\delta(\cdot)$, into a term related to changes in humidity but not circulation, a term related to changes in circulation but not humidity, a term related to changes in transient eddy fluxes, and a final term related to changes in the boundary term. ${ }^{1}$ Introducing the notation

$$
\langle\mathbf{A}\rangle^{T}=\int_{0}^{\bar{p}_{s}, T}(\boldsymbol{\nabla} \cdot \mathbf{A}) d p,
$$

where $T$ indicates the time period, that is, twentieth or twenty-first century, corresponding to the pressure data for the vertical integral. Then we have the following for the case of natural variability in the twentieth century:

$$
\begin{aligned}
\rho_{w} g \delta(\bar{P}-\bar{E}) & \approx \delta \mathrm{TH}+\delta \mathrm{MCD}+\delta \mathrm{TE}-\delta S, \\
\delta \mathrm{TH} & =-\delta\left\langle\overline{\overline{\mathbf{u}}}_{20} \hat{q}_{20}\right\rangle^{20}, \\
\delta \mathrm{MCD} & =-\delta\left\langle\hat{\mathbf{u}}_{20} \overline{\bar{q}}_{20}\right\rangle^{20}, \text { and } \\
\delta \mathrm{TE} & =-\delta\left\langle\left(\overline{\mathbf{u}^{\prime} q^{\prime}}\right)_{20}\right\rangle^{20} .
\end{aligned}
$$

The subscript 20 indicates twentieth-century values. The term influenced only by changes in humidity is called the thermodynamic term $\delta \mathrm{TH}$ and the term influenced only by changes in the mean circulation is called the dynamic term $\delta \mathrm{MCD}$. Here, $\delta \mathrm{TE}$ is the term related to changes in transient eddy fluxes and $\delta S$ is the change in the boundary term. For this case of internal variability, the difference $\delta$ is given by

$$
\delta(\cdot)=[\cdot]_{\mathrm{LN}}-[\cdot]_{\mathrm{EN}},
$$

where the square brackets with subscripts $\mathrm{EN}$ and LN indicate time averaging over months with El Niño or La Niña conditions of the quantity in parentheses. The approximate equality in Eq. (3) assumes that the vertically integrated climatological term is the same averaged over El Niño events as over La Niña events despite the differing limits on the pressure integral, that is, $\left[\left\langle\overline{\mathbf{u}}_{20} \overline{\bar{q}}_{20}\right\rangle^{20}\right]_{\mathrm{EN}} \approx\left[\left\langle\overline{\overline{\mathbf{u}}}_{20} \overline{\bar{q}}_{20}\right\rangle^{20}\right]_{\mathrm{LN}}$.

For the case of change in the mean hydrological cycle we are interested in the climatological mean $\overline{\bar{P}}-\overline{\bar{E}}$ given by

$$
\begin{aligned}
& \rho_{w} g(\overline{\bar{P}}-\overline{\bar{E}}) \\
& \quad \approx\left[-\int_{0}^{\bar{p}_{s}} \nabla \cdot(\overline{\overline{\mathbf{u}}} \overline{\bar{q}}) d p-\int_{0}^{\bar{p}_{s}} \nabla \cdot\left(\overline{\mathbf{u}^{\prime} q^{\prime}}\right) d p-\bar{q}_{s} \overline{\mathbf{u}}_{s} \cdot \nabla \bar{p}_{s}\right]_{T},
\end{aligned}
$$

where square brackets with subscript $T$ indicate time averaging over twentieth- or twenty-first-century values to form monthly climatologies. Using the definition,

\footnotetext{
${ }^{1}$ See Emori and Brown (2005) for another approach to decomposing the moisture budget within models.
} 


$$
\left[{ }^{\circ}\right]_{21}=\left[\bar{\Xi}_{20}+\Delta(\overline{\bar{*}}),\right.
$$

and writing Eq. (8) for twenty-first- and twentiethcentury means and subtracting we have the following:

$$
\begin{aligned}
\rho_{w} g \Delta(\overline{\bar{P}}-\overline{\bar{E}}) \approx \Delta \mathrm{TH}+\Delta \mathrm{MCD}+\Delta \mathrm{TE}-\Delta S, \\
\Delta \mathrm{TH}=-\left\langle\overline{\mathbf{u}}_{20} \Delta \overline{\bar{q}}\right\rangle^{21}, \\
\Delta \mathrm{MCD}=-\left\langle\Delta \overline{\overline{\mathbf{u}}}_{20}\right\rangle^{21}, \text { and } \\
\Delta \mathrm{TE}=-\Delta\left\langle\overline{\overline{\mathbf{u}}^{\prime} q^{\prime}}\right\rangle^{\mathrm{T}} .
\end{aligned}
$$

In this case for the approximations to hold $\left\langle\overline{\mathbf{u}}_{20} \overline{\bar{q}}_{20}\right\rangle^{21} \approx$ $\left\langle\overline{\overline{\mathbf{u}}}_{20} \overline{\bar{q}}_{20}\right\rangle^{20}$. Both this and the prior approximation were evaluated and indeed introduce errors, in general, an order of magnitude smaller than the terms retained.

For the hydrological cycle change the procedure and results are as in SNV and we use annual mean data for 2046-65 minus 1961-2000. For internal hydrological cycle variability we conduct an empirical orthogonal function (EOF) analysis of the annual mean $\bar{P}-\bar{E}$ field. Because ENSO is centered on the boreal winter season we use July to June to define the year. The first EOF in all models is the representation of ENSO and variously explains $15 \%-49 \%$ of the total variance of $\bar{P}-\bar{E}$ with a mean of $32 \%$ (as compared to $32 \%$ in the $20 \mathrm{CR}$ discussed below). To compute differences we take the associated principal component and compute composites for when it is above one standard deviation and composites for when it is below one standard deviation. The difference, $\delta(\cdot)=[\cdot]_{\mathrm{LN}}-[\cdot]_{\mathrm{EN}}$, is the difference between the two composites chosen to be of the sign of La Niña minus El Niño. This separation into patterns of forced change and natural variability would not work if radiative forcing caused a shift toward more El Niño- or La Niñalike $P-E$ patterns. However, there is no evidence from IPCC AR4/CMIP3 models that this occurs (Coelho and Goddard 2009), the pattern of tropical SST change is quite different to that for El Niño (Liu et al. 2005) and, as shall be shown, the patterns of modeled hydroclimate change and variability are quite different. For both hydrological cycle change and variability we only show the 15 model ensemble mean.

\section{Mechanisms of modeled hydrological cycle variability and change}

\section{a. Comparing the modeled patterns of $P-E$} variability and change

Figure 1 (left column) shows the change in $\overline{\bar{P}}-\overline{\bar{E}}$ from the twentieth to the twenty-first century in response to changes in radiative forcing. There is widespread drying in the subtropics and extending into the equatorward flanks of the midlatitudes. There is a wetting trend over the equatorial Pacific and Indian Oceans. The multimodel mean first EOF of $\bar{P}-\bar{E}$ for the 15 models' simulations of the twentieth century is shown in the right column. This pattern clearly represents the models' version of ENSO variability with, for the La Niña phase shown here, reduced precipitation across the equatorial Pacific Ocean and increased precipitation in the tropics to the north, west, and southwest and over the equatorial Atlantic Ocean. During the model La Niña phases the subtropics to midlatitudes are, in general, dry including over SWNA. This multimodel mean pattern is very similar to the observed pattern of ENSO-forced precipitation variability (e.g., Seager et al. 2005a).

Anthropogenic change and La Niñas are both associated with widespread subtropical to midlatitude drying but the former is accompanied by increased $\overline{\bar{P}}-\overline{\bar{E}}$ and the latter by decreased $\bar{P}-\bar{E}$ over the equatorial Pacific Ocean. The anthropogenic subtropical drying is also flanked on the poleward side by moistening in both hemispheres, which is not seen in the natural variability. Both patterns have a strong zonally symmetric component although, for natural variability, there is an east-west dry-wet feature over the North Pacific Ocean in contrast to the southnorth dry-wet pattern of anthropogenic change.

\section{b. The dynamical and thermodynamical contributions to natural variability of, and forced changes in, modeled $P-E$}

Figure 1 also shows the thermodynamic, dynamic, and transient eddy contributions to the forced change and natural variability of $P-E$. As noted before (HS; SNV; Seager and Vecchi 2010), the thermodynamic component $(\mathrm{TH})$ is very important for the forced change. This follows simply from rising specific humidity in a warming atmosphere, which causes the pattern of moisture divergence and convergence by the mean flow to intensify making already wet areas wetter and already dry areas drier. The mean circulation dynamics (MCD) contribution to forced change is also important and acts to weaken the pattern of $\overline{\bar{P}}-\overline{\bar{E}}$ in the tropics as the tropical circulation weakens (Vecchi and Soden 2007). The MCD term also provides a drying on the poleward flank of the subtropics as the Hadley Cell expands and the storm tracks shift poleward (SNV). The transient eddy term contribution to forced change is weaker but also contributes to subtropical drying as moisture transport strengthens and the storm tracks shift poleward.

The contributions to natural variability of $\bar{P}-\bar{E}$ are quite different and the major term by far is the MCD term (note the use of an uneven contour interval in Fig. 1). This 


\section{Climate Change} $\delta(P-E)$

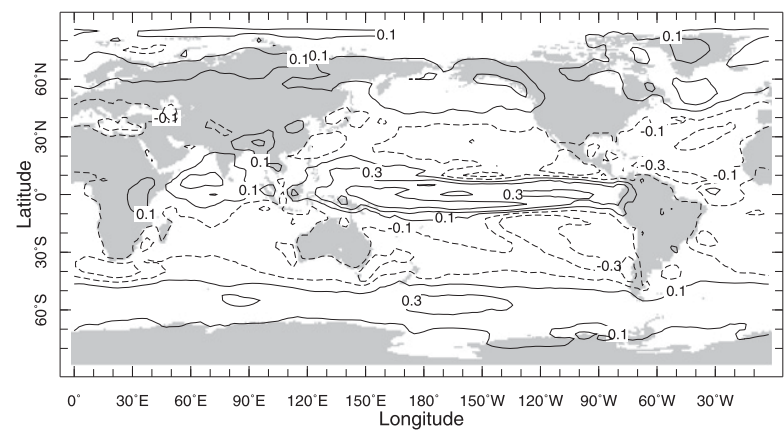

$\delta T H$

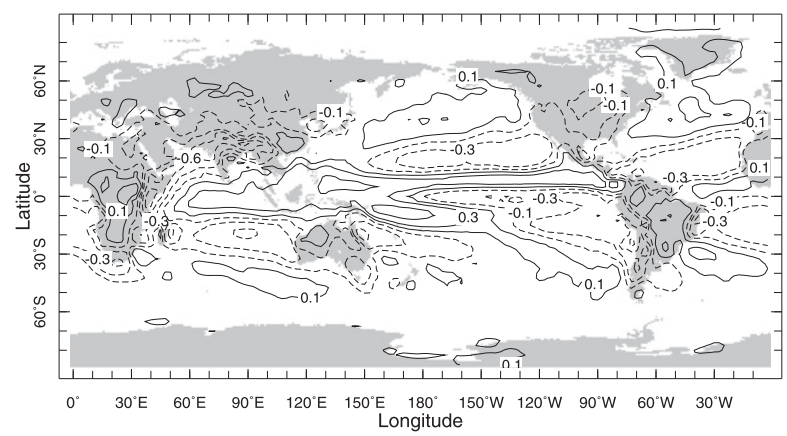

$\delta M C D$

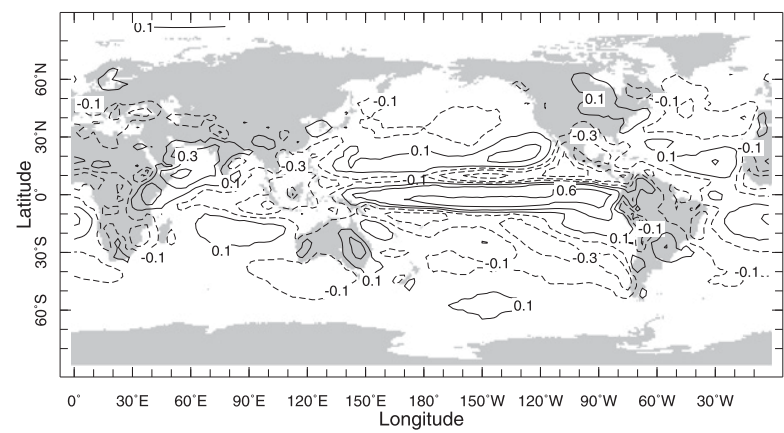

$\delta T E$

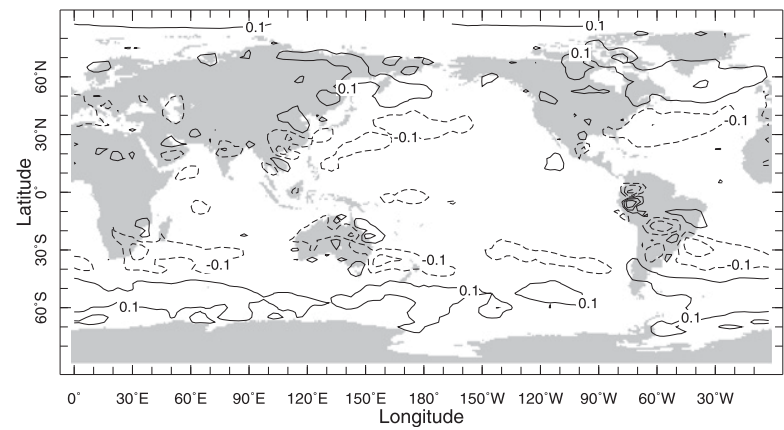

Natural Variability

$\delta(P-E)$

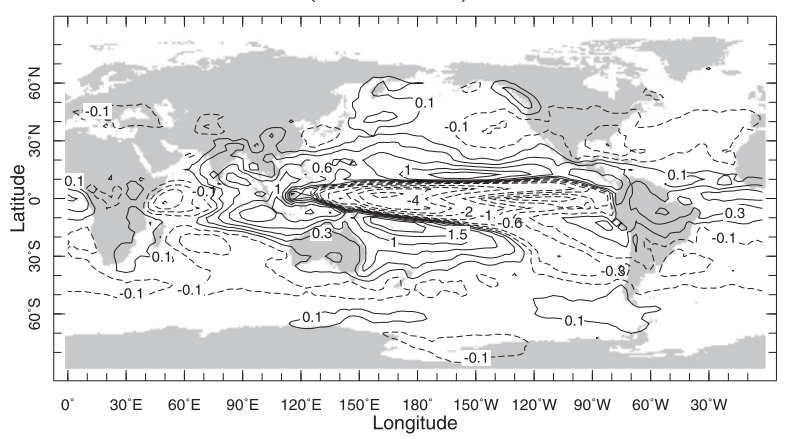

$\delta T H$

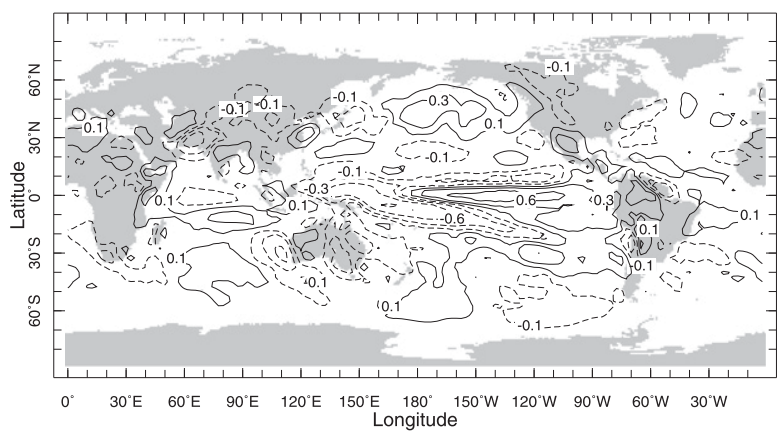

$\delta M C D$

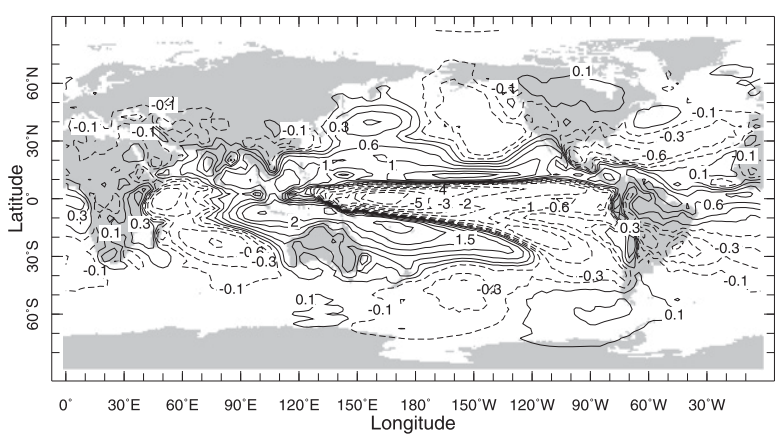

$\delta T E$

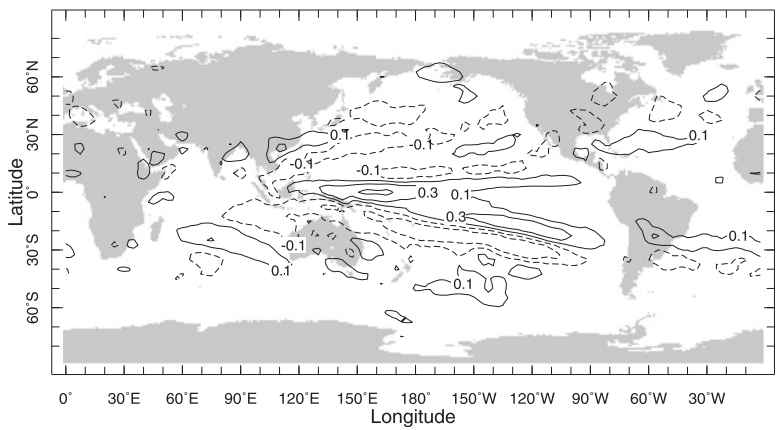

FIG. 1. (left) The multimodel ensemble mean change in $\bar{P}-\bar{E}$ for 2046-65 minus 1961-2000 and the contributions to it from (top to bottom) changes in the thermodynamic TH, mean circulation dynamics MCD, and transient eddies TE terms, and (right) as in the left column, but for natural-modeled ENSO variability with the sign convention of La Niña minus El Niño. Units are $\mathrm{mm}^{-1}{ }^{-1}$. 
dominates the tropical change in $\bar{P}-\bar{E}$ with increased moisture divergence over the cold tropical Pacific waters and increased moisture convergence elsewhere that are related to the strengthening of the Walker Circulation during La Niña events and a westward shift of its ascending branch (Bjerknes 1969). The MCD term is also dominant in the extratropics explaining, for example, the drying during La Niña from the west Pacific across North America and the subtropical North Atlantic Ocean and the drying over the midlatitude Southern Hemisphere oceans. The extratropical circulation anomalies responsible for the MCD-related $\bar{P}-\bar{E}$ anomalies arise from 1) transient eddy momentum flux anomalies driving subtropical-midlatitude descent and 2) rising and descending low-level flow within the Rossby wave train forced by tropical heating anomalies (Seager et al. 2003, 2005a; Seager 2007). In contrast, the TH term is in almost all places several times smaller than the MCD term indicating that changes in specific humidity are not very important to explaining the natural variability of $\bar{P}-\bar{E}$. The change in the transient eddy contribution to natural $\bar{P}-\bar{E}$ variability is also quite small.

This analysis supports the idea that, although both $\mathrm{La}$ Niña conditions in the tropical Pacific and GHG-driven global warming can cause widespread subtropical to midlatitude drying, the mechanisms involved are distinct. The natural variability can be characterized as dynamics dominated in that the $\bar{P}-\bar{E}$ variability is to first order explained by variations in the circulation with variations in specific humidity playing a secondary role. The anthropogenic, rising GHG-driven, change can, instead, be characterized as "thermodynamics mediated" in that the consequences of the rise in specific humidity are very important but that changes in circulation also play an important role.

\section{Analysis of contributions to natural variability of $\bar{P}-\bar{E}$ in the 20CR}

Next, we assess whether the natural variability of $\bar{P}-\bar{E}$, and the contributions to it, within the IPCC AR4/CMIP3 models, are comparable to those in the 20CR. Using the post-1979 period we compute the first EOF of the annual mean $\bar{P}-\bar{E}$ field in the 20CR and then composite into times when the associated principal component (PC) was above plus one standard deviation and times when it was below minus one standard deviation. Figure 2 shows the composited La Niña minus El Niño $\bar{P}-\bar{E}$ difference and the contributions to it from the TH, MCD, and TE terms. Figure 3 (top) shows the time evolution of the first $\bar{P}-\bar{E}$ EOFs together with the time series of the Niño$3.4 \mathrm{SST}$ index $\left(\mathrm{SST}\right.$ averaged over $5^{\circ} \mathrm{S}-5^{\circ} \mathrm{N}, 120^{\circ}-170^{\circ} \mathrm{W}$ ) and the close correlation between them is quite clear.
The pattern of $\bar{P}-\bar{E}$ variability is very similar to that obtained from the multimodel ensemble mean. One difference is that the equatorial Pacific region of negative $\bar{P}-\bar{E}$ during La Niña only extends west to the west Pacific warm pool unlike the cross-Pacific equatorial drying in the models. This is symptomatic of model ENSO SST anomalies that also extend too far west. In the 20CR there is (correctly) increased $\bar{P}-\bar{E}$ over the west Pacific warm pool during La Niñas. The widespread subtropical to midlatitude drying during La Niñas is seen in the 20CR, as in the models, with the additional east-west dry-wet dipole across the North Pacific Ocean as well. As in the models, the $\bar{P}-\bar{E}$ variations are dominantly forced by the MCD term. The 20CR change in transient eddy flux contributions to $\bar{P}-\bar{E}$ is much noisier than in the models, as expected given the single realization in the $20 \mathrm{CR}$.

The second $\bar{P}-\bar{E}$ EOF (not shown) is also centered in the tropical Pacific Ocean and has an east-west dipole in $\bar{P}-\bar{E}$ and accounts for the more eastward displaced $\bar{P}-\bar{E}$ (and SST) anomaly patterns in large El Niño events (e.g., 1982/3 and 1997/8, Fig. 3). The higher-order EOFs do not seem to represent significant large-scale modes of variability.

The multimodel ensemble mean and 20CR patterns of natural variability of, and contributions to, $\bar{P}-\bar{E}$ are quite similar. This is so even though the former is a purely coupled model product while the latter is constrained by the observed SST and surface pressure patterns. This provides some confidence that the models faithfully represent observed internal hydrological cycle variability, at least in the ensemble mean. Consequently, the clear distinction in the models between mechanisms of forced and internal $P-E$ change and variability is also genuine.

\section{Relation of natural variability and forced change in $\boldsymbol{P}-\boldsymbol{E}$ to atmospheric circulation}

As discussed in the introduction subtropical-extratropical drying during La Niña events and radiatively-forced change involve a poleward shift of the jet streams and storm tracks. This has a sizable zonally symmetric component and next we show the patterns of zonal mean variability of, and forced change in, zonal wind and temperature (Fig. 4) and vertical pressure velocity (Fig. 5). The climate change signal is one of overall warming with maxima in the tropical and subtropical upper troposphere and at lower levels in northern polar regions. Associated with this are strengthened zonal mean zonal winds centered at about $50^{\circ} \mathrm{N}$ and $50^{\circ} \mathrm{S}$ as well as a westerly trend in the tropical and subtropical upper troposphere. The pattern of natural variability within the IPCC AR4/CMIP3 models also has westerly anomalies at about $50^{\circ} \mathrm{N}$ and $50^{\circ} \mathrm{S}$ but has easterly anomalies equatorward of there on 

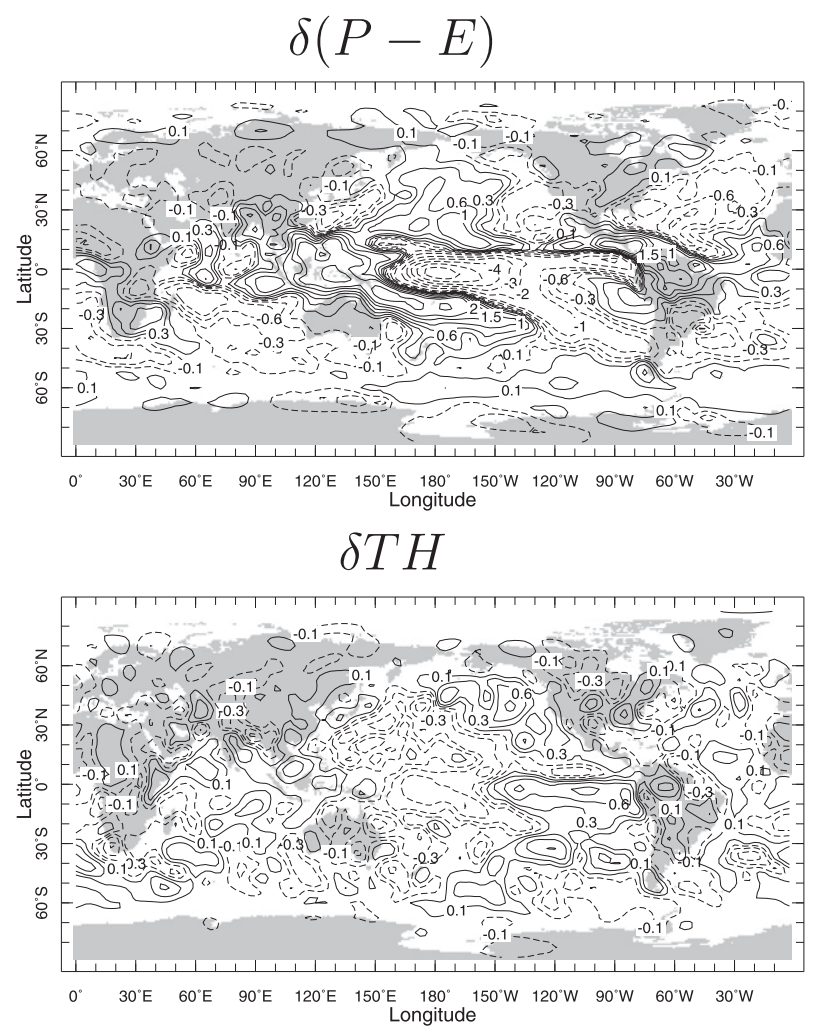

$\delta M C D$

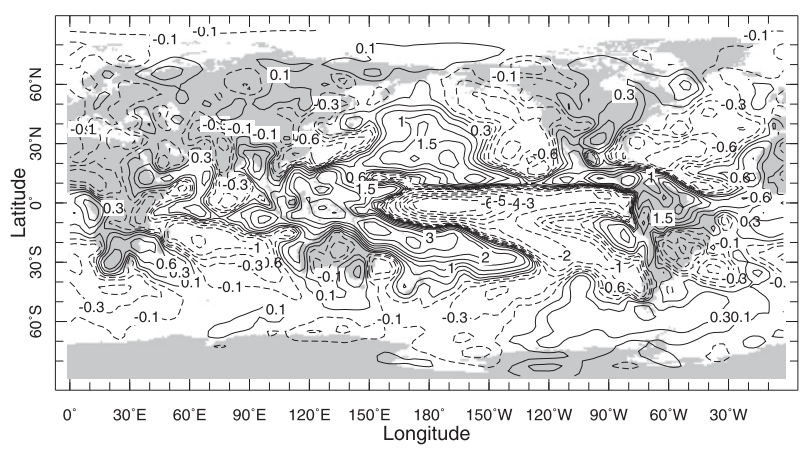

$\delta T E$

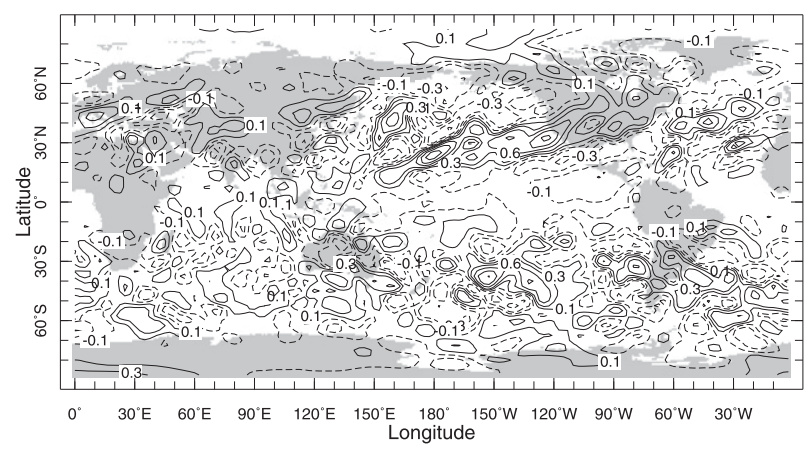

FIG. 2. The first mode of $\bar{P}-\bar{E}$ variability in the 20CR and the contributions to it from (top to bottom) changes in the thermodynamic the poleward flanks of the tropical upper-tropospheric cooling associated with La Niña conditions. The pattern of natural variability in the $20 \mathrm{CR}$ is similar to the models but with much stronger midlatitude warm anomalies (see Seager et al. 2003). Hence, there is a clear distinction between the global atmospheric state of La Niñas and global warming despite the common attribute of poleward shifted jets.

For the vertical pressure velocity (Fig. 5) both natural variability and climate change in the IPCC AR4/CMIP3 models have subsidence at the poleward edge of the subtropics and into the extratropics, which is responsible for drying there. However, for natural variability associated with La Niñas, we also see a weakened Hadley Cell in both the models and the 20CR while for climate change the models also show the southward shifted Northern Hemisphere intertropical convergence zone (ITCZ).

\section{Separating internal variability from forced change of $P-E$ in the post-1979 climate record}

Next, we turn to the 20CR and the SST-forced CCM3 model ensemble to attempt to determine the contributions of internal variability and forced change to post-1979 $\bar{P}-\bar{E}$ history. The internal variability due to large-scale atmosphere-ocean variability is represented by the first two modes only, whose time evolutions were shown in Fig. 3. The procedure then is to compute the $\bar{P}-\bar{E}$ field explained by the sum of these two modes and subtract this from the total $\bar{P}-\bar{E}$ field to obtain a residual $\bar{P}-\bar{E}$ field. The residual field contains any climate "noise" that is not captured by the first two modes and also any potential climate change that does not have the spatial pattern of the modes of internal variability. That is,

$$
\bar{P}-\bar{E}=\sum_{n=1}^{2} a_{n}(t) p_{n}(x, y)+(\bar{P}-\bar{E})_{R},
$$

where $\bar{P}-\bar{E}$ is a space (longitude $x$ and latitude $y$ ) and time $(t)$ dependent field, $a_{n}(t)$ are the time series of the two spatial patterns, $p_{n}(x, y)$, of $\bar{P}-\bar{E}$ variability determined by the EOF analysis and $(\bar{P}-\bar{E})_{R}$, is the residual field. Using the total, internal variability, and residual fields

TH, mean circulation dynamics MCD, and transient eddies TE terms with the sign convention of La Niña minus El Niño. Results are for the difference of years composited together when the associated principal component was beyond one standard deviation of the mean. Units are $m m$ day $^{-1}$. 
20CR PCs and NINO3-4 index

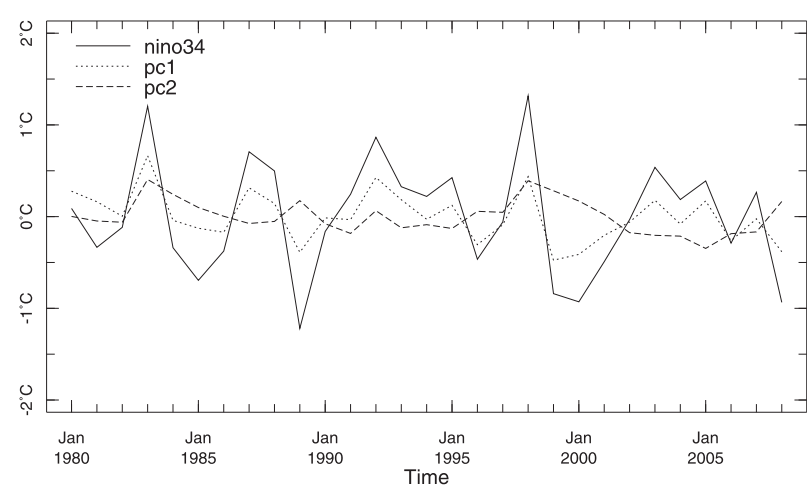

GOGA PCs and NINO3-4 index

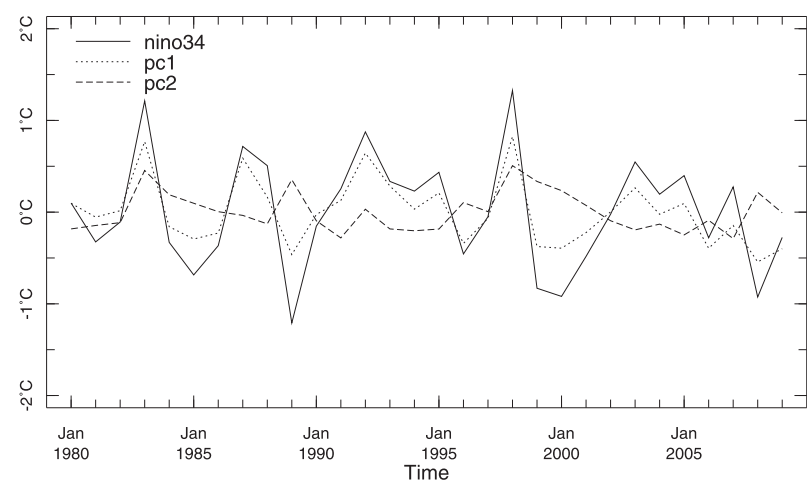

FIG. 3. The time series of principal components 1 and 2 of the EOF analysis of (top) 20CR and (bottom) $\bar{P}-\bar{E}$ anomalies together with the Niño-3.4 tropical Pacific SST index.

we compute the linear trends of each over 1979 to the final date (March 2010 for CCM3 and December 2008 for 20CR).

The patterns and zonal means of the 20CR trends are shown in Fig. 6. Amidst considerable noise, there is widespread drying in the tropical Pacific Ocean and moistening over the Indian Ocean and Maritime Continent regions. Further, there is a dipole of subtropical drying and midlatitude moistening at all longitudes in the Southern Hemisphere. The Northern Hemisphere also shows some evidence of subtropical drying (e.g., over the eastern Pacific, southwest North America, and the Atlantic Ocean) but this is less clear than in the Southern Hemisphere. The pattern of the 20CR trend in $\bar{P}-\bar{E}$ is similar to that of satellite and gauge precipitation (Hoerling et al. 2010; Seager and Vecchi 2010).

The part of this trend that projects onto patterns of natural variability (Fig. 6, middle panel) also shows the drying in the central and eastern tropical Pacific and moistening over the Maritime Continent region. It also shows the subtropical drying but little in the way of moistening further poleward. These are characteristic of a trend toward more La Niña-like conditions over the post-1979 period. The zonal mean has equatorial drying and moistening at the latitude of the Northern Hemisphere ITCZ. The trend in the residual (Fig. 6, bottom panel) actually has moistening at the equator and a decline in $\bar{P}-\bar{E}$ at the latitude of the Northern Hemisphere ITCZ. The residual trend also has Southern Hemisphere subtropical drying and higher-latitude moistening indicating that the total Southern Hemisphere trend in $\bar{P}-\bar{E}$ can only partly be accounted for by natural variability and that some part could arise from climate change. The largest values of the trends are typically smaller than the natural variability but, nonetheless, some of the major features of the total, natural variability, and residual trends are significant albeit above only the $90 \%$ level. Because of averaging across some longitudinal variability, much of the zonal mean trends are significant above this level. $^{2}$

To check the validity of these results we perform the same analysis on the 16-member CCM3 ensemble mean. The time evolutions of the two CCM $3 \bar{P}-\bar{E}$ modes are also shown in Fig. 3 (bottom) and are also clearly related to ENSO. The three CCM3 trends are shown in Fig. 7. Differences between the CCM3 trend and the 20CR trend are expected due to differences in the models used, only the 20CR has time-varying radiative forcing, the CCM3 data is for an ensemble mean that isolates the SST-forced trend whereas the reanalysis trend, through surface pressure assimilation, also includes the full influence of atmospheric variations that were not SST forced. Despite that, there are clear similarities between the two trends. The equatorial drying in the east and central Pacific and moistening in the Maritime Continent and tropical Atlantic regions are both estimates of the post-1979 trend. Further, both show subtropical drying and midlatitude moistening in the Southern Hemisphere. In the Northern Hemisphere drying occurs in both estimates from the eastern subtropical Pacific across the United States and Atlantic and into the Mediterranean region. Since the CCM3 GOGA model is only forced by SST variations, any agreement of $\bar{P}-\bar{E}$ trends with those in 20CR is suggestive of the influence of SST while disagreements could suggest a direct influence of changing trace gas contents which are also included in 20CR. Statistical significance of the CCM3 GOGA trends is less than for 20CR because the former has larger amplitude natural variability.

\footnotetext{
${ }^{2}$ Statistical significance as shown here was assessed assuming that the annual means were independent. Allowing for the weak serial correlation leads to only very small changes in the areas of statistical significance.
} 


\section{MMM temperature (colors), zonal wind (contours)}

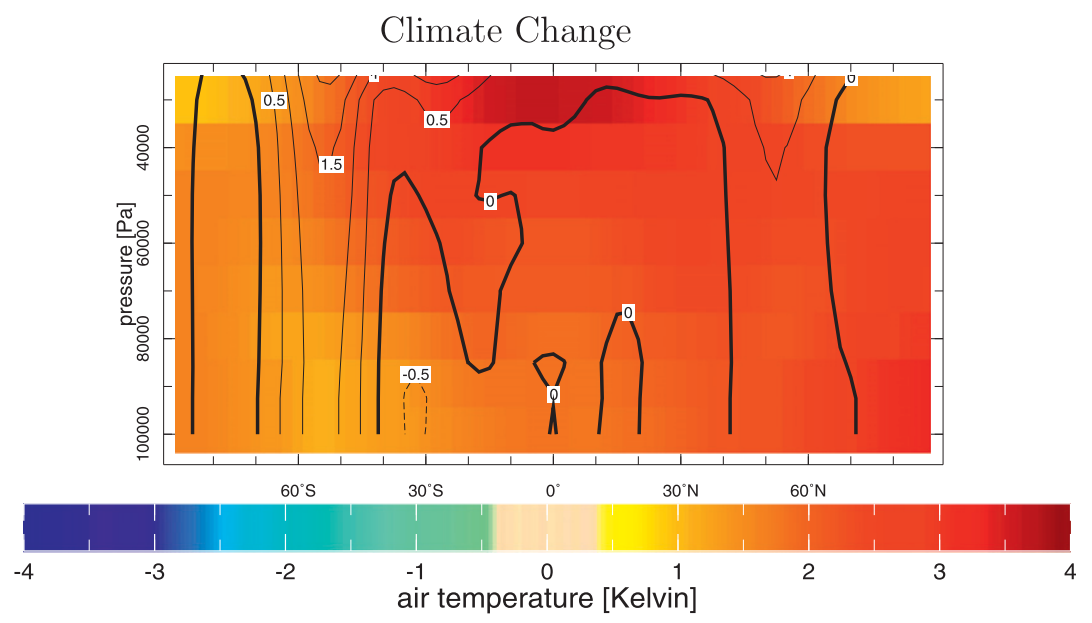

Natural Variability

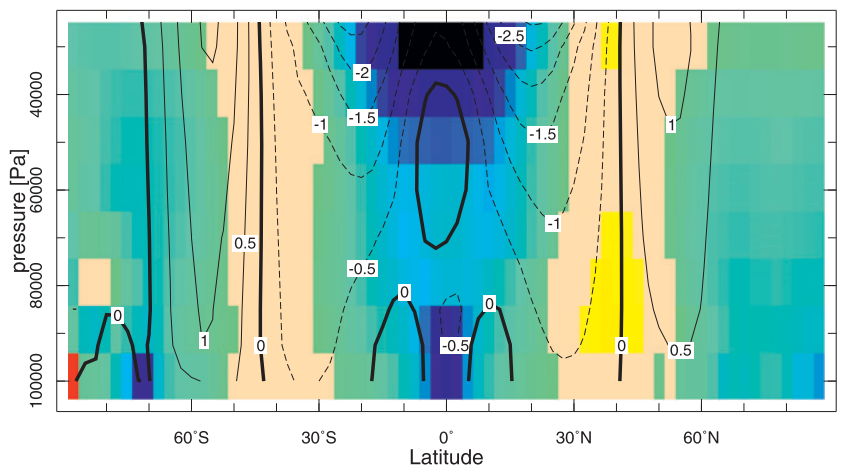

20CR temperature (colors), zonal wind (contours)

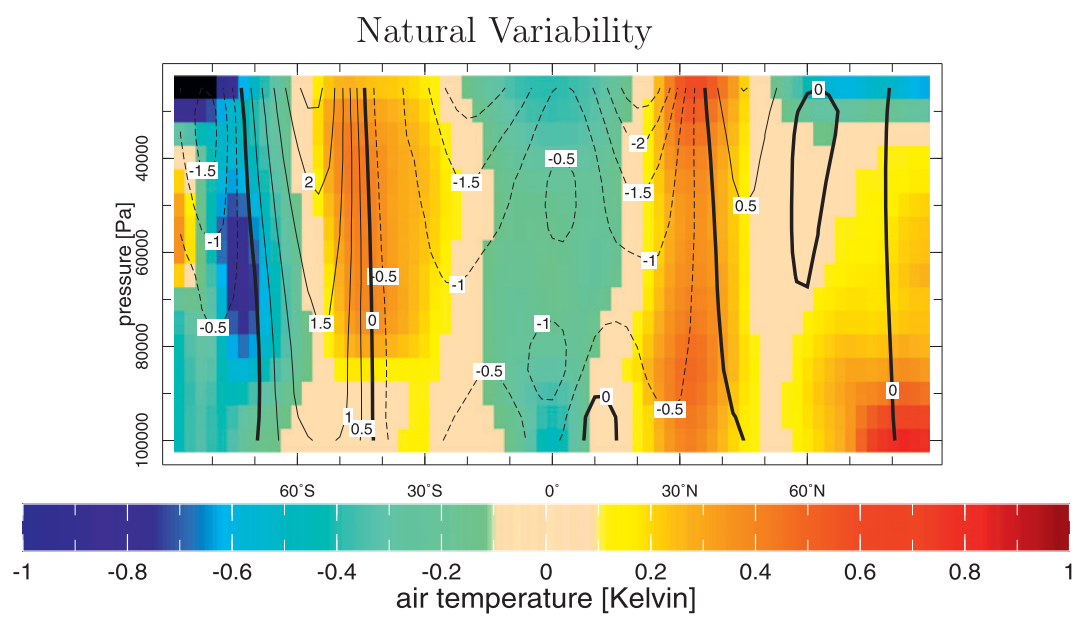

FIG. 4. The zonal mean zonal velocity (contours) and temperature (colors) for (top) the twentieth- to twenty-first-century climate change, (middle) associated with the first PC of natural variability, both within the IPCC AR4/CMIP3 models, and (bottom) associated with

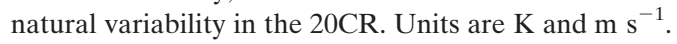


MMM omega $(=d p / d t)$

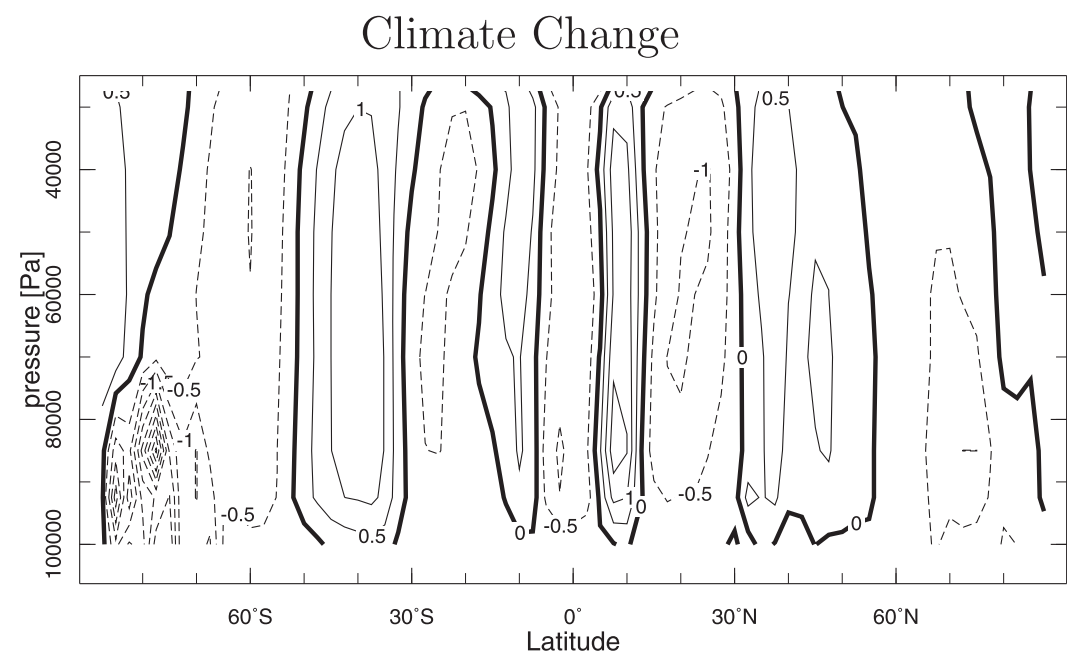

Natural Variability

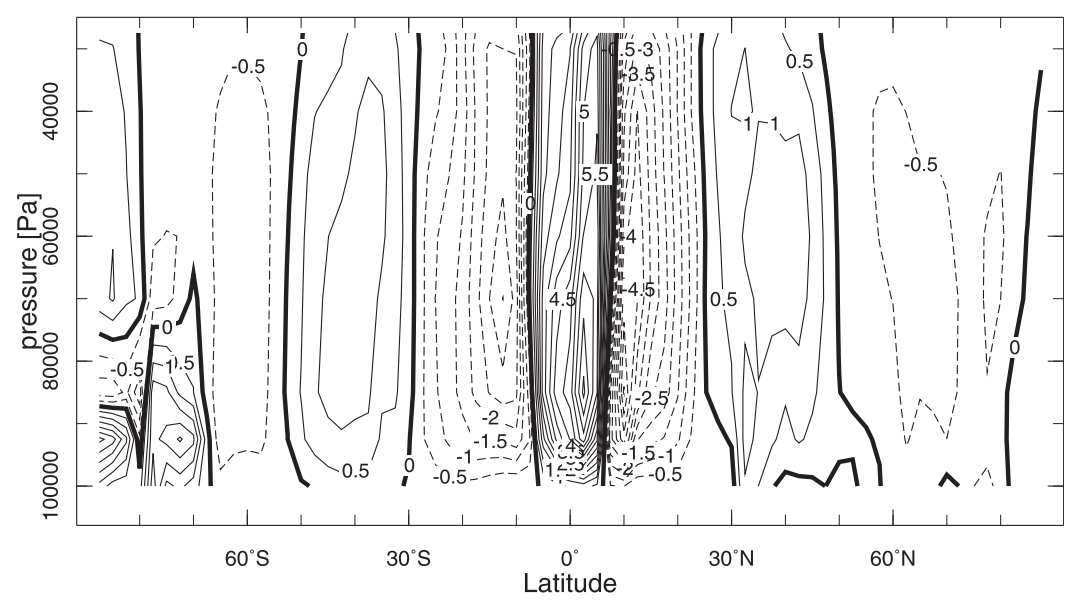

20CR omega $(=d p / d t)$

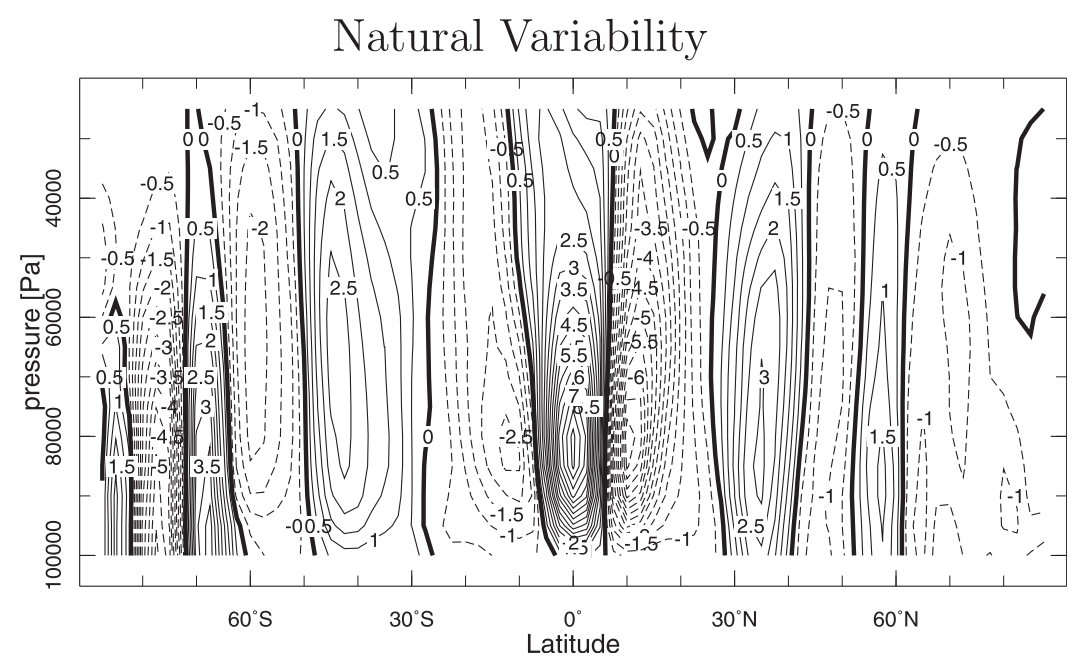

FIG. 5. As in Fig. 4, but for vertical pressure velocity. Units are hPa day ${ }^{-1}$. 
Total trend
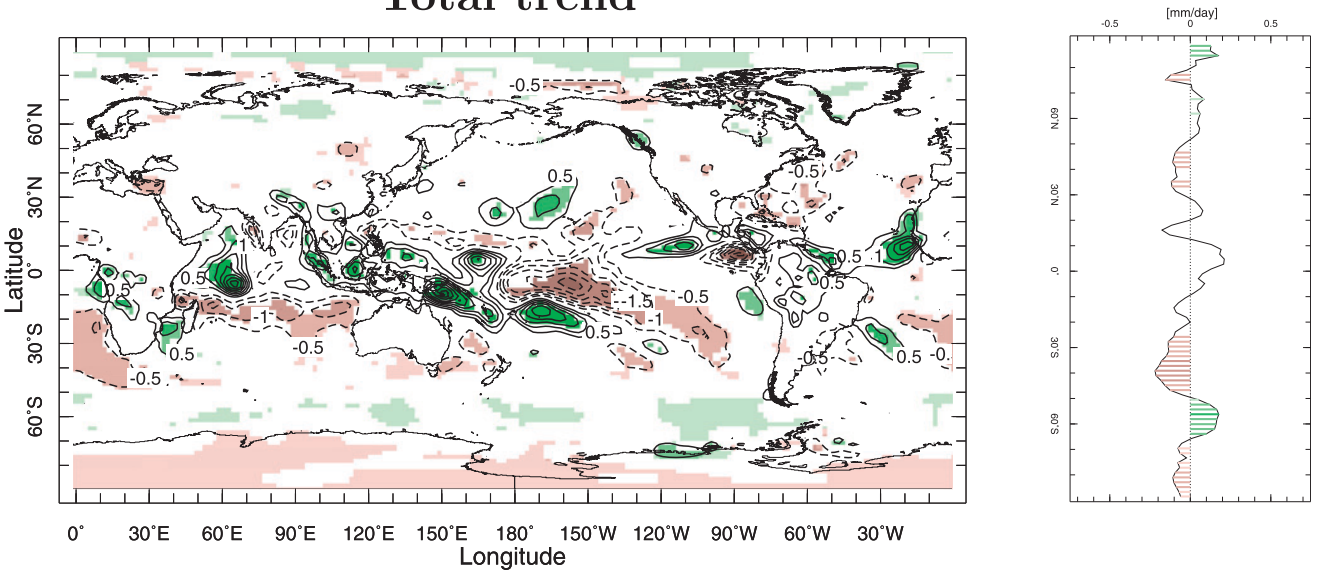

\section{trend in projection on natural variability}
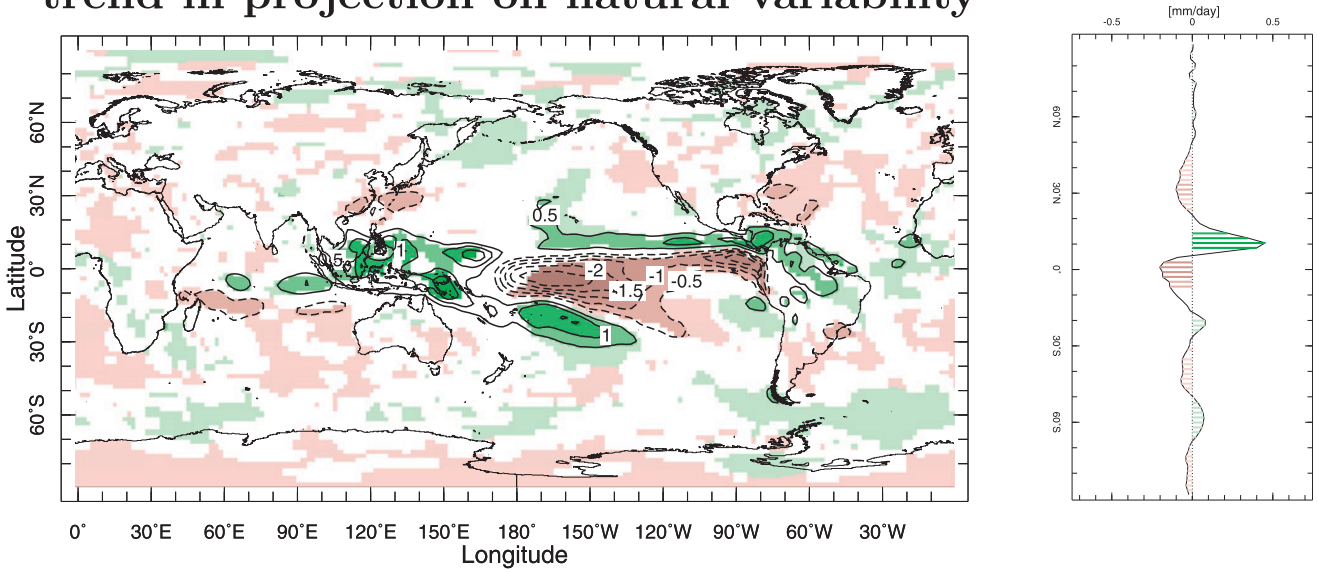

\section{trend in residual}

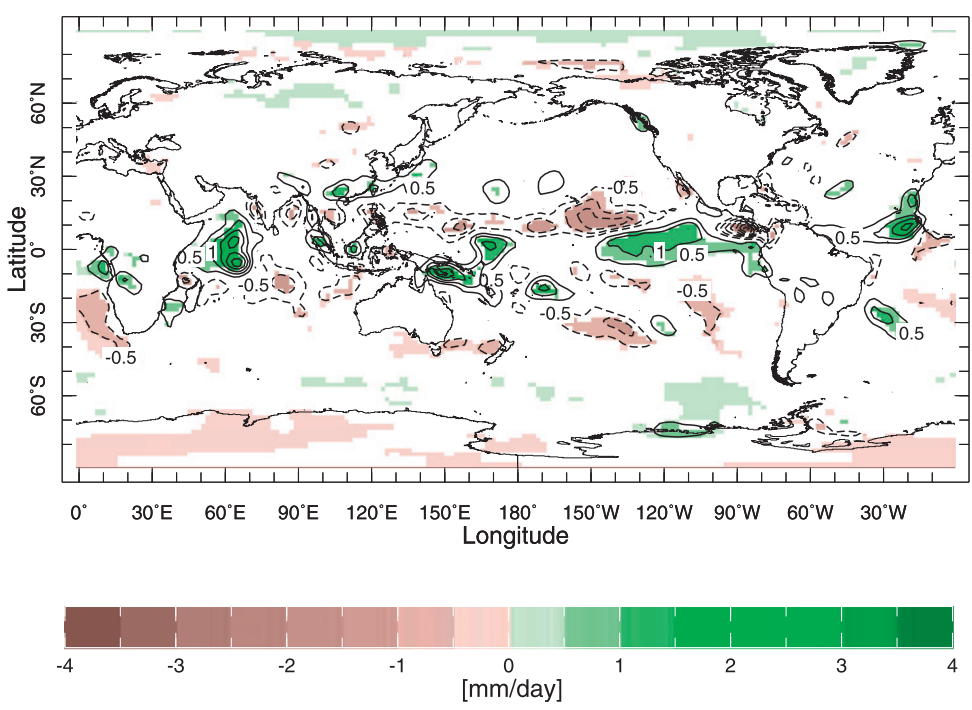

FIG. 6. (top) The actual post-1979 20CR $\bar{P}-\bar{E}$ trend, (middle) the part due to ENSO variability, and (bottom) the residual. (right) Zonal means are shown. For all panels shading indicates statistical significance above the $90 \%$ confidence level. Units are $\mathrm{mm}_{\text {day }}{ }^{-1}$ change over the $1979-2008$ period. 


\section{Total trend}
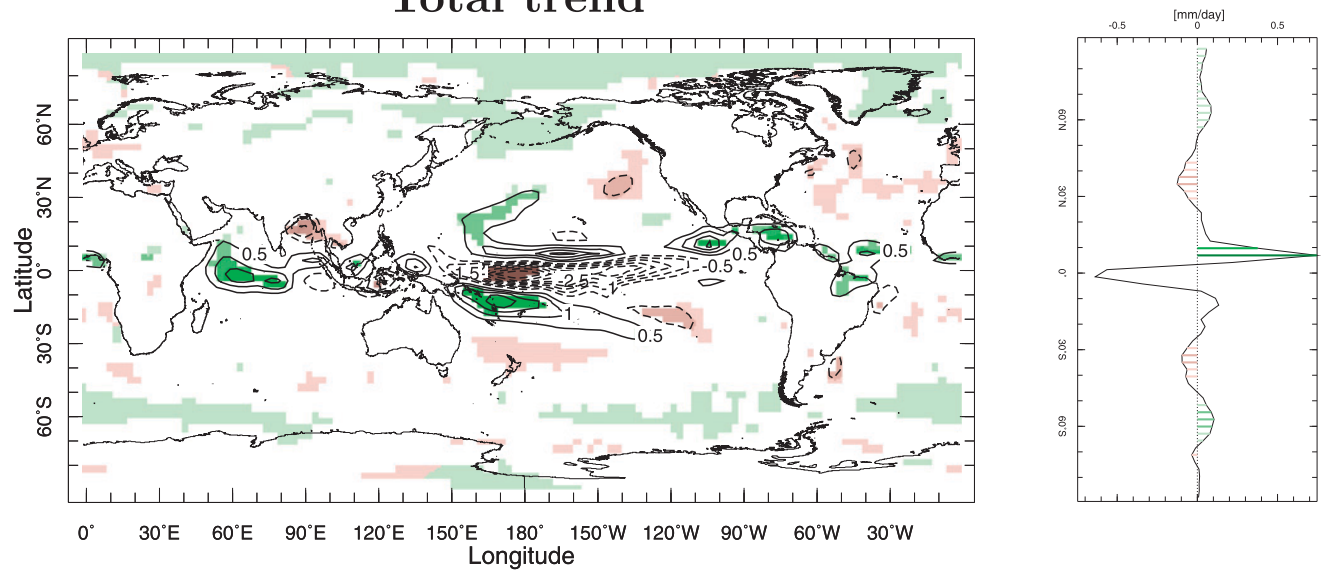

trend in projection on natural variability
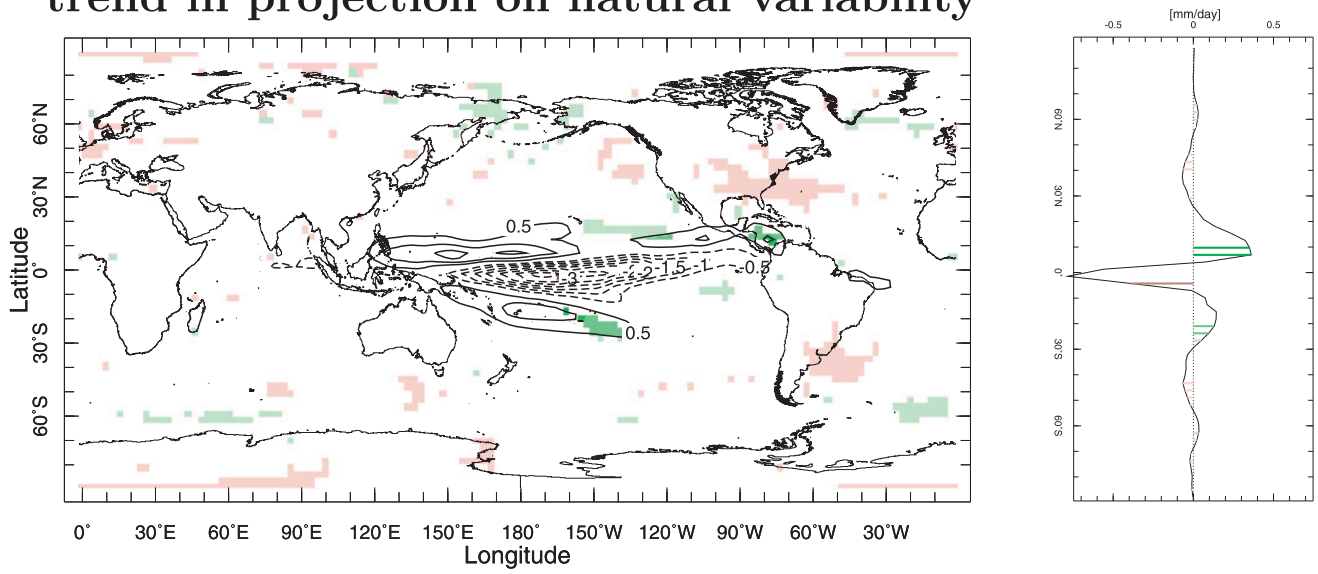

trend in residual
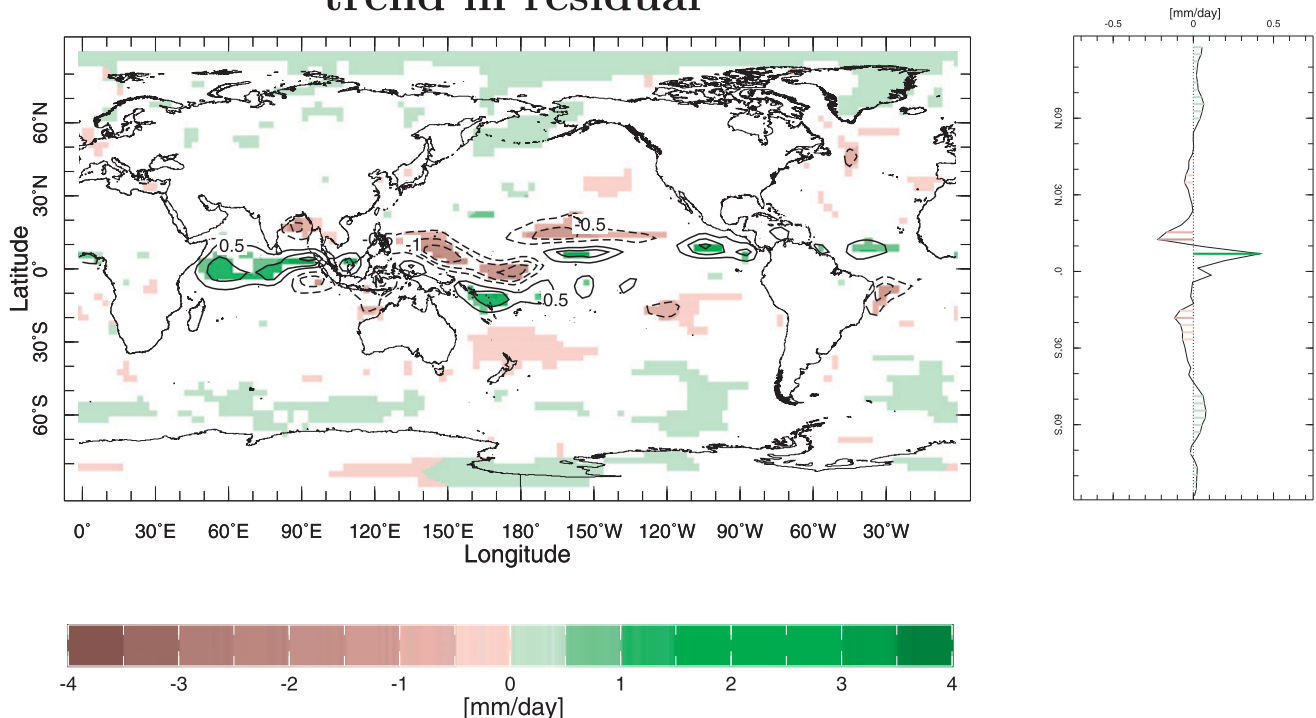

FIG. 7. (top) The actual post-1979 SST-forced GOGA model $\bar{P}-\bar{E}$ trend, (middle) the part due to ENSO variability, and (bottom) the residual. (right) Zonal means are shown. For all panels shading indicates statistical significance above the $90 \%$ confidence level. Units are $\mathrm{mm}_{\text {day }}{ }^{-1}$ change over the 1979 to 2008 period. 


\section{Total trend}

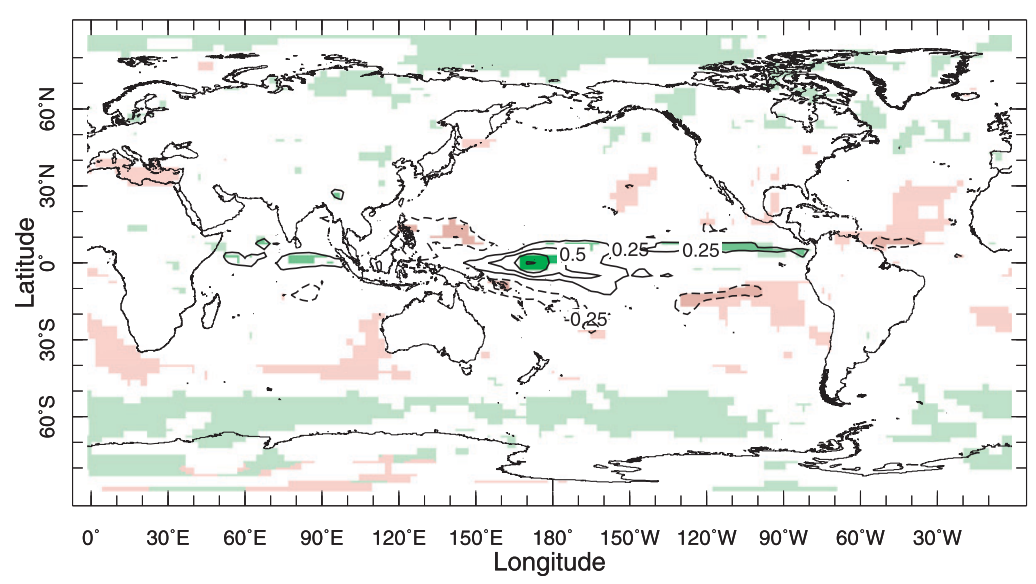

FIG. 8. The multimodel mean $\bar{P}-\bar{E}$ trend over 1979 to 2008 averaged across 15 IPCC AR4/CMIP3 models. (right) The zonal mean is shown. For both panels shading indicates statistical significance above the $90 \%$ confidence level. Units are mm day ${ }^{-1}$ change over the $1979-2008$ period. The contour interval is 0.25 compared to 0.5 in prior figures.

The part of the trend that projects onto the patterns of internal variability is different between the two estimates because of model differences in the $\bar{P}-\bar{E}$ response to tropical Pacific SST variations. Nonetheless the two patterns are quite similar with a classic La Niña-like trend with equatorial Pacific drying, wetting in the $\mathrm{Pa}-$ cific ITCZ and South Pacific convergence zone, subtropical drying in the Southern Hemisphere and, in the Northern Hemisphere, from the east Pacific across the Atlantic and into the Middle East. In contrast, both the 20CR and the CCM3 model residual trends show increased near-equatorial precipitation and subtropical drying and some indication of higher-latitude moistening all of which cannot be accounted for by internal variability.

In Fig. 8 we show, for comparison, the 1979-2010 trend in $\bar{P}-\bar{E}$ computed from the multimodel average of the IPCC AR4/CMIP3 runs. This is a model-based estimate of the purely radiatively forced trend given that averaging across 15 models should quite effectively remove the internal variability that is not common across the individual models. It shows a wetting trend in the equatorial Pacific and Indian Oceans, drying trends in the subtropics, and a hint of a wetting trend in higher latitudes. This trend has the same pattern as seen for the twentiethto twenty-first-century projected change (Fig. 1 and see also HS; SNV) but, at this early stage of anthropogenic influence, is considerably weaker. However, there is a clear resemblance to the residual trends in the 20CR and the CCM3 model, suggesting that the latter truly are influenced by anthropogenic change. Consistent with the 20CR and GOGA model, only some areas of the IPCC AR4/ CMIP3 trends are significant above the $90 \%$ level but most of the zonal mean trends reach this level of significance.

\section{Mechanisms of post-1979 changes in $\bar{P}-\bar{E}$}

The analysis so far has revealed that post-1979 trends in $\bar{P}-\bar{E}$ are strongly influenced by internal ENSOrelated variability over the period. When this influence is removed two estimates of the atmospheric state agree that the equatorial region has moistened and the subtropical regions have dried, broadly consistent with the IPCC AR4/CMIP3 estimate of the radiatively forced change to date. Next, we compute the mechanisms responsible for the post-1979 residual trend in $\bar{P}-\bar{E}$ and compare these to the mechanisms of radiatively forced change in the coupled models, as diagnosed in section 3. An agreement between the $\bar{P}-\bar{E}$ trend and the mechanisms responsible would constitute strong evidence that the post-1979 residual trend is radiatively forced.

To proceed, we decompose the 20CR and CCM3 moisture budgets into parts due to internal variability and the residual as

$$
\begin{aligned}
\bar{P}-\bar{E} \approx & \sum_{n=1}^{2} a_{n}(t)\left(\mathrm{TH}_{n}+\mathrm{MCD}_{n}+\mathrm{TE}_{n}\right) \\
& +\mathrm{TH}_{R}+\mathrm{MCD}_{R}+\mathrm{TE}_{R} .
\end{aligned}
$$

The first three terms on the right-hand side of this equation describe the components of the internal variability contribution to the $\bar{P}-\bar{E}$ history, and the last three terms describe the components of the residual contribution. The procedure is to obtain the spatial fields $\mathrm{TH}_{n}$, $\mathrm{MCD}_{n}$, and $\mathrm{TE}_{n}$ by regressing the time-dependent fields $\mathrm{TH}, \mathrm{MCD}$, and TE onto the time series $a_{n}(t)$. The residual time-dependent fields, $\mathrm{TH}_{R}, \mathrm{MCD}_{R}$, and $\mathrm{TE}_{R}$ are found by subtracting $a_{1} \mathrm{TH}_{1}+a_{2} \mathrm{TH}, a_{1} \mathrm{MCD}_{1}+a_{2} \mathrm{MCD}_{2}$, and 
$a_{1} \mathrm{TE}_{1}+a_{2} \mathrm{TE}_{2}$ from the full fields TH, MCD, and TE, respectively. Post-1979 trends in the $\mathrm{TH}_{R}, \mathrm{MCD}_{R}$, and $\mathrm{TE}_{R}$ contributions to the residual $\bar{P}-\bar{E}$ trend are then computed.

For both the 20CR and the CCM3 model the maps (not shown) of $\mathrm{TH}_{R}$, the residual trend in the thermodynamic component of $\bar{P}-\bar{E}$ change, it is hard to discern anything but noise. In contrast, the IPCC AR4/CMIP3 multimodel mean (computed by averaging this term across the 15 models) shows a small $\mathrm{TH}_{R}$ tendency to moistening in the ITCZ and drying in the subtropics. This term involves the increase in specific humidity and the unchanging circulation so, as expected, this constitutes an intensification of the existing $\bar{P}-\bar{E}$ pattern as in HS and SNV.

Figure 9 shows the trends in the $\mathrm{MCD}_{R}$ component of residual $\bar{P}-\bar{E}$ change. Weakening of the tropical circulation (Vecchi and Soden 2007) would be expected to create a negative $\bar{P}-\bar{E}$ tendency in regions of mean ascent (the ITCZ and monsoons) and a positive $\bar{P}-\bar{E}$ tendency in regions of mean descent (the descending branches of the Walker Circulation and Hadley Cell). This is seen in the IPCC AR4/CMIP3 multimodel mean and is similar to that shown in Fig. 1. In the equatorial Pacific a positive $\bar{P}-\bar{E}$ tendency due to the MCD term is also contributed to by a southward shift of the ITCZ (see $\mathrm{SNV}$ ). Amidst considerable noise, this basic pattern is also seen in the MCD terms of the 20CR and, to some extent, the CCM3 model. The IPCC AR4/CMIP3 multimodel mean for 2046-65 relative to 1961-2000 shows MCDinduced drying at the poleward fringe of the subtropics (caused by the poleward expansion of the Hadley Cell) but this is only hinted at in the Southern Hemisphere in the post-1979 trends. The change in the residual and multimodel mean $\bar{P}-\bar{E}$ trend due to transient eddies lacks spatial coherence and is not shown.

Much of the change in $\bar{P}-\bar{E}$ projects onto the zonal mean so, for a simplified picture, in Fig. 10 we show the zonal mean trends in the residual $\bar{P}-\bar{E}$ and the $\mathrm{TH}_{R}$, $\mathrm{MCD}_{R}$, and $\mathrm{TE}_{R}$ contributions to it, for the 20CR, the CCM3 model, and the IPCC AR4/CMIP3 multimodel mean. For $\bar{P}-\bar{E}$ there is actually substantial agreement between the three datasets with equatorial wetting and drying at the latitude of the ITCZ and in the southern subtropics with moistening again at higher latitudes, although the amplitude of these changes vary amongst the different estimates of the atmospheric state. For $P-E$ the pattern correlation between the multimodel mean and 20CR is 0.71 and between the CCM3 GOGA model and the multimodel mean is 0.64 . The importance of the change in the $\mathrm{MCD}_{R}$ term to the tropical trends in residual $\bar{P}-\bar{E}$ are clear while the $\mathrm{TH}_{R}$ contribution does hint at the wet getting wetter, dry getting drier character of change. The $\mathrm{TE}_{R}$ contribution has some suggestion of drying of the tropics and subtropics and moistening at higher latitudes as expected. The lack of clarity of most of these features of post-1979 change, relative to the changes seen in Fig. 1 for 2046-65, is of course due to the small size of the anthropogenic hydroclimate change to date. Nonetheless, the work does suggest the anthropogenic-induced change is emerging and detectable.

\section{Relation of the ENSO-removed residual trends in $\overline{\boldsymbol{P}}-\overline{\boldsymbol{E}}$ to trends in circulation and atmospheric and oceanic thermodynamic state}

More understanding of the trend in $\bar{P}-\bar{E}$ that emerges after removal of the ENSO influence, and whether it is anthropogenic, can be gained by examining its relation to SSTs, atmospheric circulation, and thermodynamic structure. For each of these quantities the total field is regressed onto the time series of the first two modes of $\bar{P}-\bar{E}$ variability and these components are then removed to create a residual field for which the linear trend is computed. Figure 11 shows the total trend in SST from the 20CR and the residual trend after the part projecting onto patterns of internal variability has been removed together with the IPCC AR4/CMIP3 multimodel mean SST trend. The total trend in the 20CR has general warming north of $60^{\circ} \mathrm{S}$, especially in the northern mid and polar latitudes, but cooling in a broad region of the east and central tropical Pacific Ocean reflecting the more La Niña-like conditions after the 1997/98 El Niño. Removing the ENSO-related internal variability produces a residual trend (middle panel) that has weak warming in the eastern and central equatorial Pacific Ocean and somewhat weaker warming in the midlatitudes. [The cooling over Antarctica in the 20CR is not seen in the National Centers for Environmental Prediction/National Center for Atmospheric Research Reanalysis (Kistler et al. 2001).] The residual trend is similar to the IPCC AR4/CMIP3 multimodel mean trend with the exception of regional details and greater observed warming over the North Atlantic Ocean (probably related to the trend in Atlantic multidecadal variability Ting et al. 2009), and the East Siberian, Chukchi, and Beaufort Seas region of the Arctic.

The $\mathrm{MCD}_{R}$ term is important to radiatively forced tropical $\bar{P}-\bar{E}$ change because of the weakening of the overturning circulation and the equatorward shift of the Pacific ITCZ. In Fig. 12 we show the total trend in the 20CR, the residual trend after ENSO influence has been removed, and the IPCC AR4/CMIP3 multimodel mean trend of zonal mean vertical velocity. The total trend has little well defined structure in the tropics, some large-amplitude changes over Antarctica, and a dipole of downward motion around $30^{\circ}-50^{\circ} \mathrm{S}$ and upward 


\section{CR, residual}

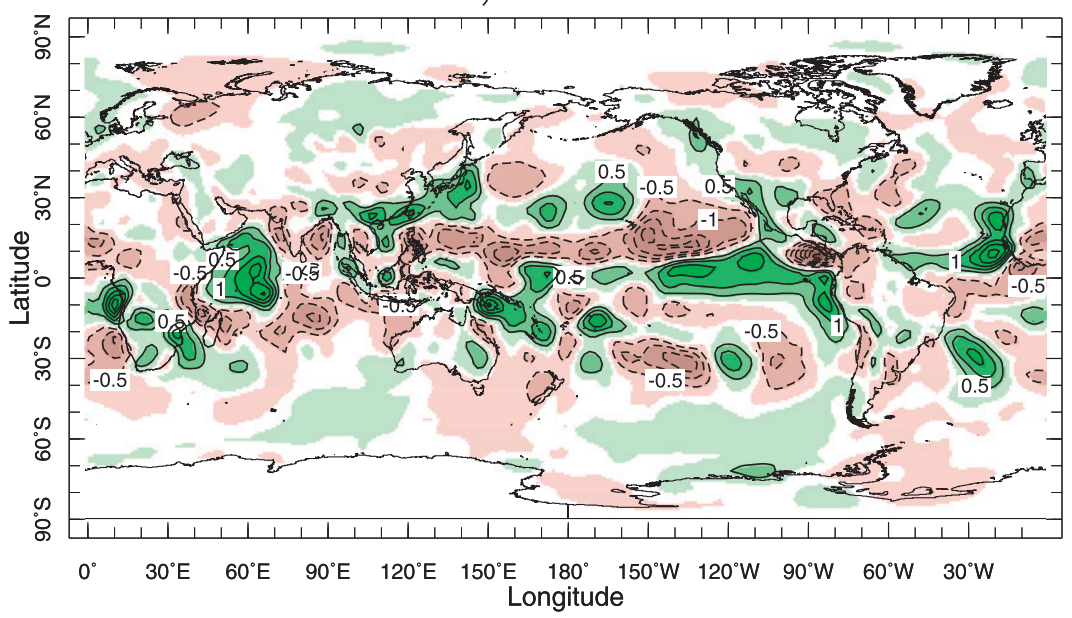

\section{GOGA, residual}

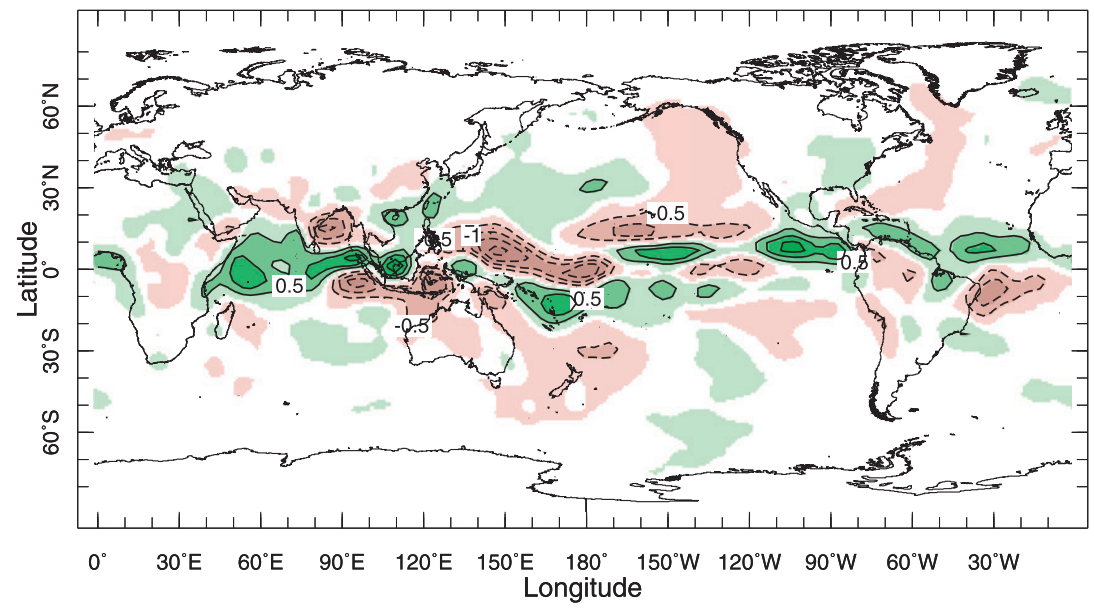

\section{MMM}

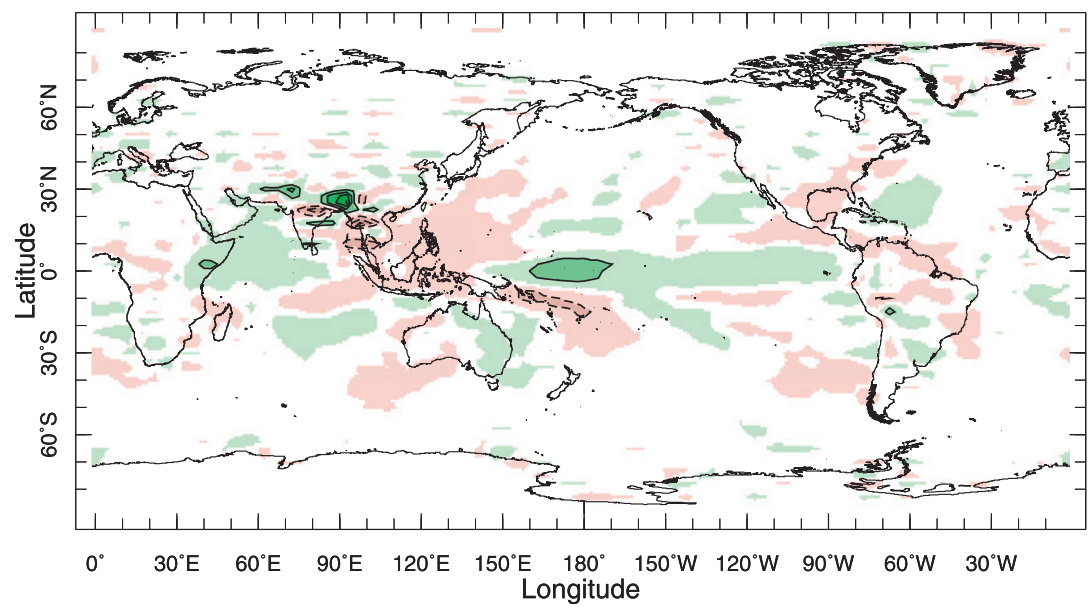

FIG. 9. The post-1979 mean circulation dynamics contribution to the 1979-2008 residual $\bar{P}-\bar{E}$ trends for (top) the 20CR, (middle) the SST-forced GOGA model, and (bottom) the IPCC AR4/CMIP3 multimodel mean. Units are mm day ${ }^{-1}$ change over the 1979-2008 period. 
$P-E$

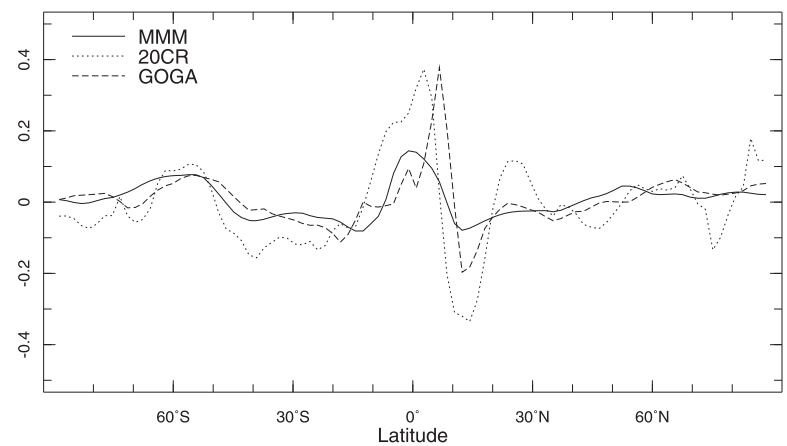

TH

$M C D$
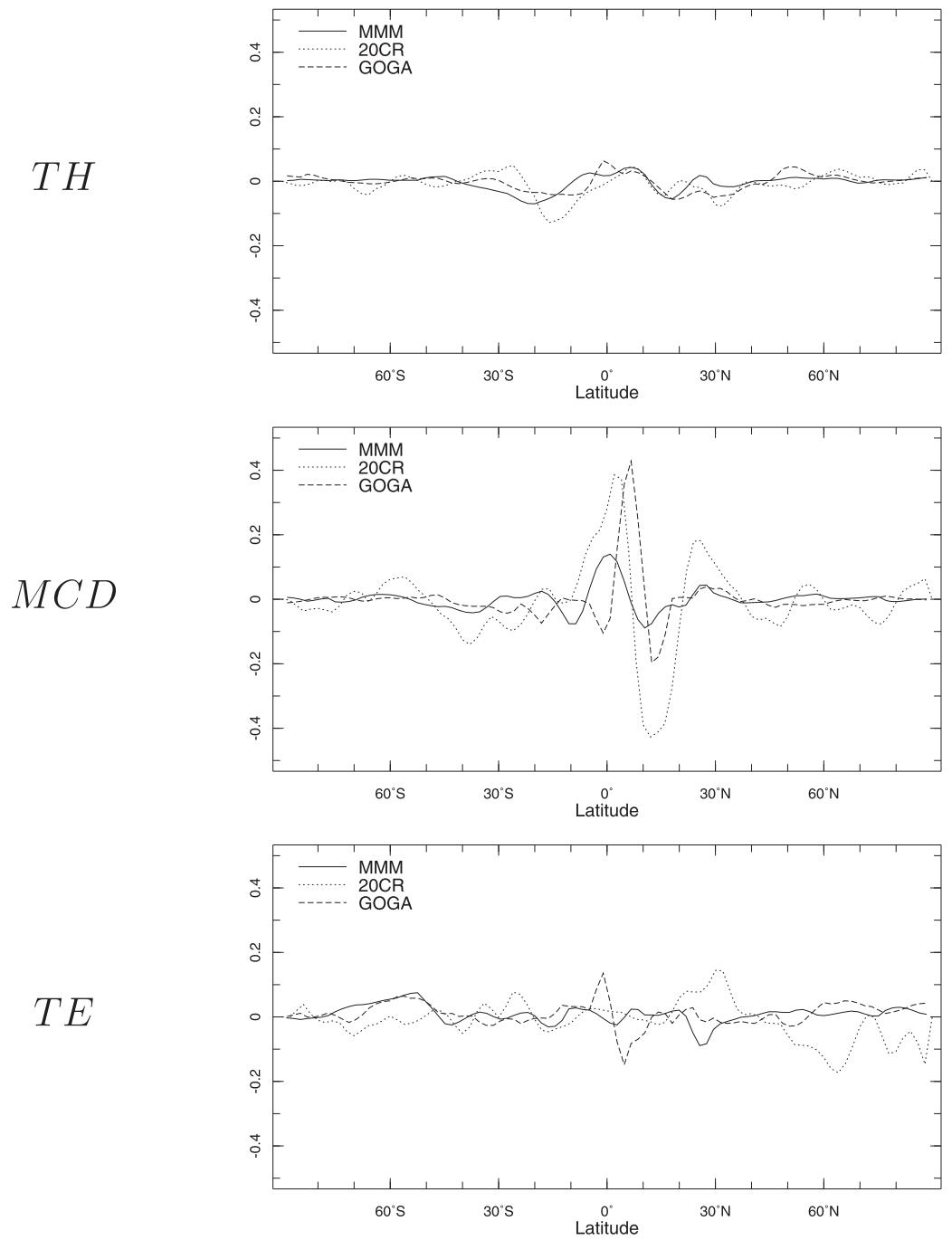

FIG. 10. The zonal mean residual trends of $P-E$ from the 20CR and GOGA model and the multimodel mean IPCC AR4/CMIP3 trend and the thermodynamic TH, mean circulation dynamics MCD, and transient eddy TE contributions to each. Units are mm day ${ }^{-1}$ change over the 1979-2008 period.

motion around $50^{\circ}-65^{\circ} \mathrm{S}$. After the influence of ENSO is removed the residual trend actually shows upward motion at the equator and downward motion immediately to the north. The southern midlatitudes dipole remains but is weakened. The IPCC AR4/CMIP3 multimodel mean trend also shows the upward motion at the equator and downward motion to the north, as in the 20CR, but has an additional region of downward motion south of 


\section{CR total trend}

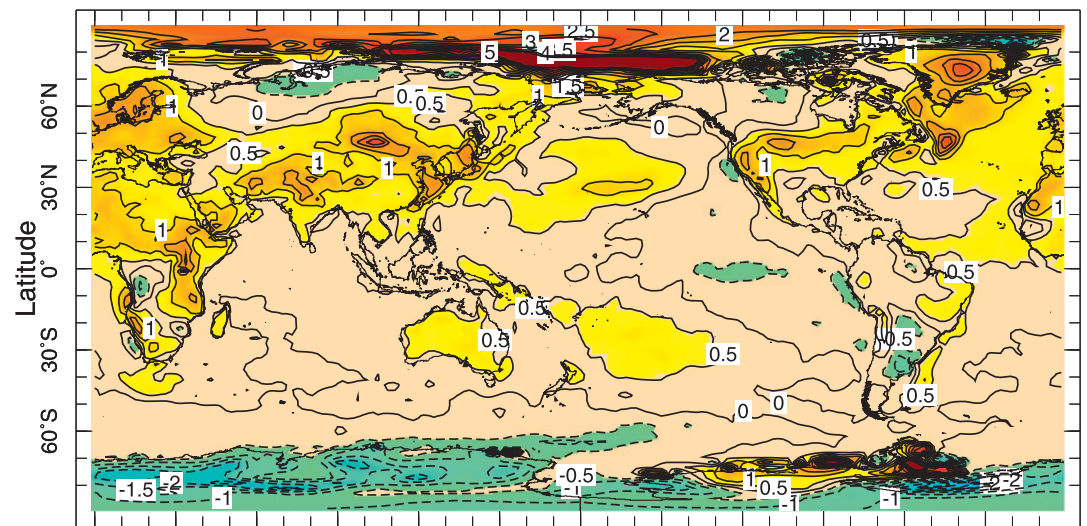
$0^{\circ} \quad 30^{\circ} \mathrm{E} \quad 60^{\circ} \mathrm{E} \quad 90^{\circ} \mathrm{E} \quad 120^{\circ} \mathrm{E} \quad \begin{gathered}150^{\circ} \mathrm{E} \quad 180^{\circ} \\ \text { Longitude }\end{gathered}$

\section{CR trend in residual}

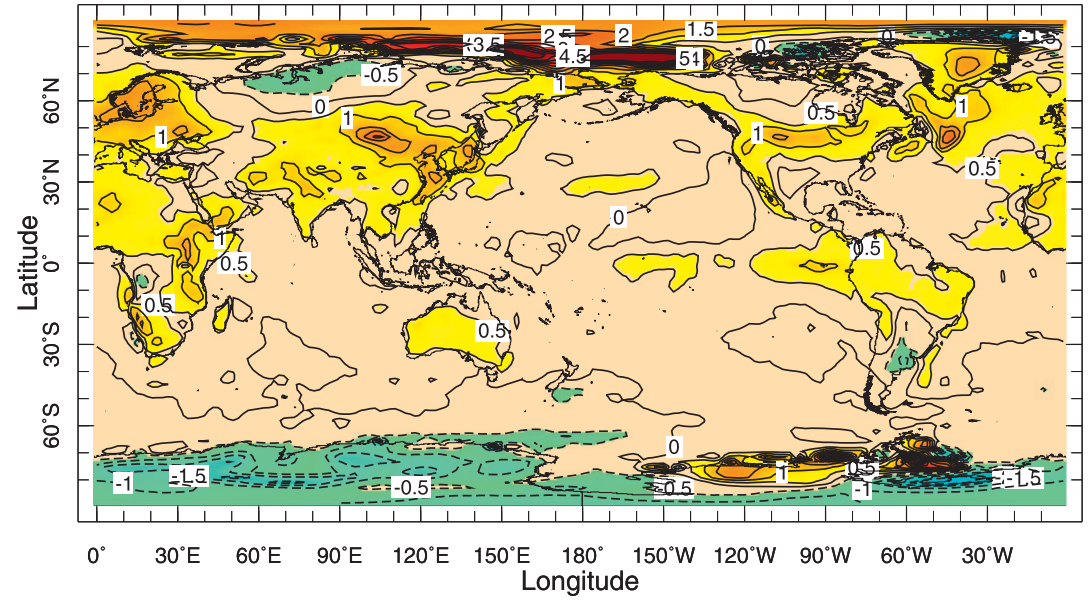

MMM trend

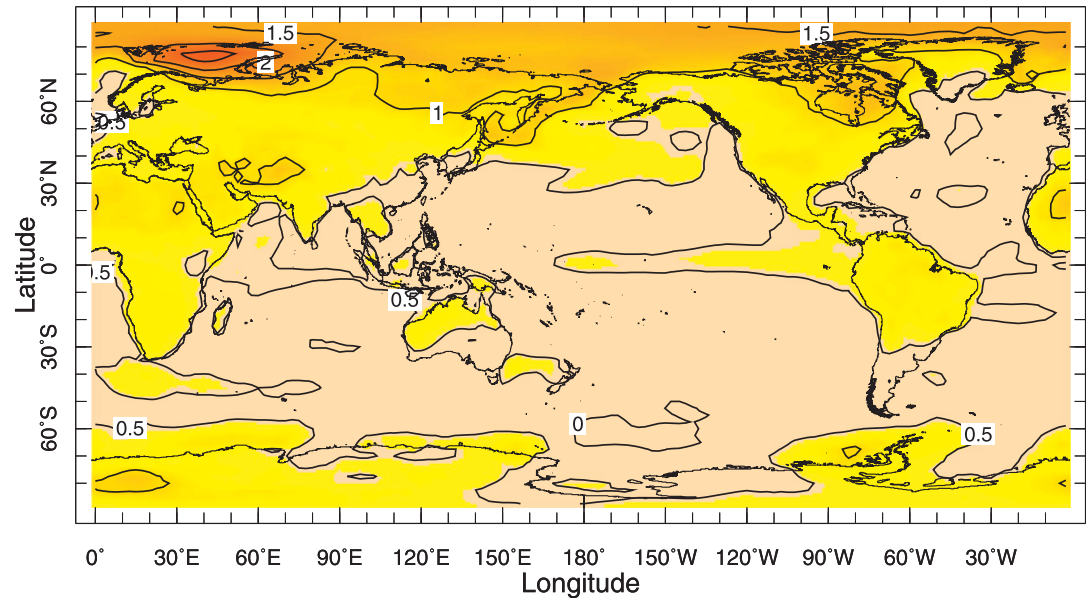

FIG. 11. The 1979-2008 20CR surface temperature trend, the residual trend from the reanalysis after ENSO influences have been removed, and the multimodel ensemble mean from the IPCC AR4/CMIP3 models. Units are change in K over the 1979-2008 period. 


\section{CR total trend}

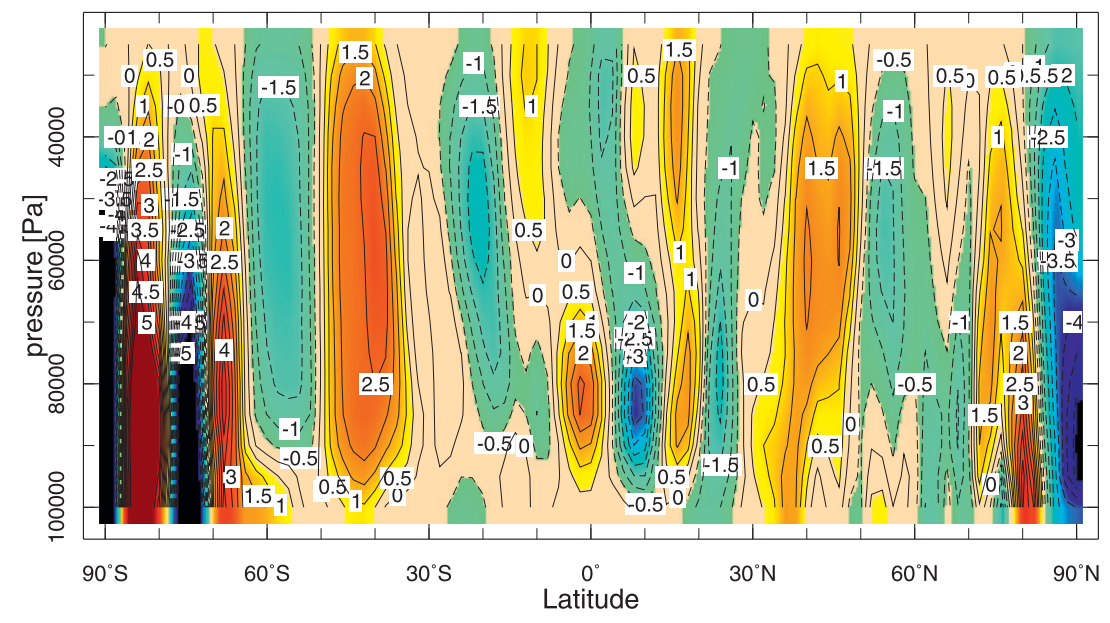

20CR trend in residual

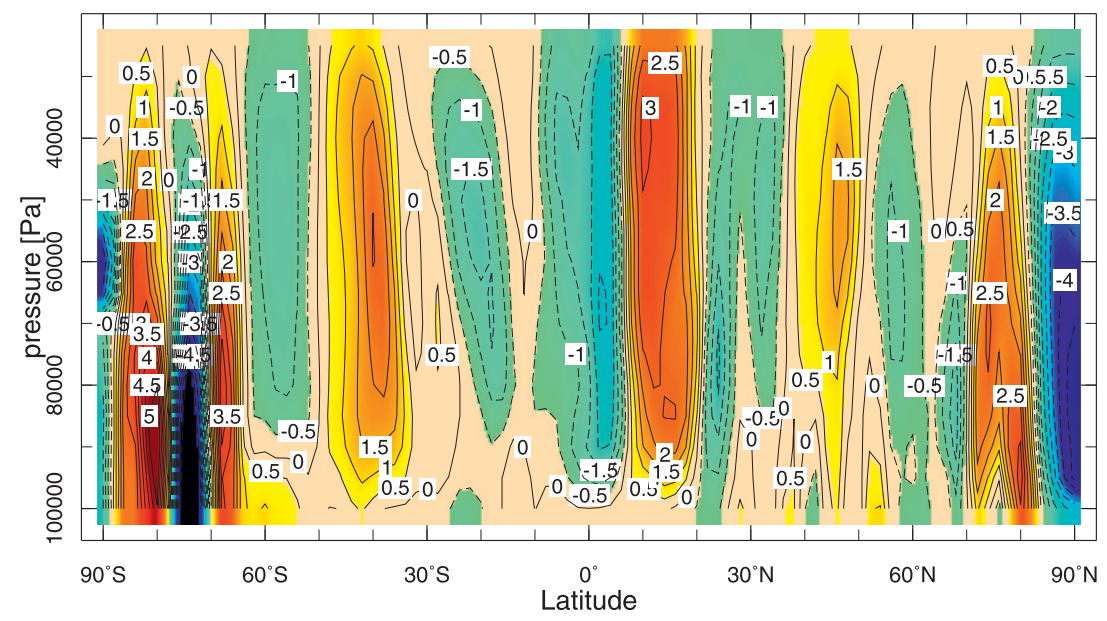

MMM trend

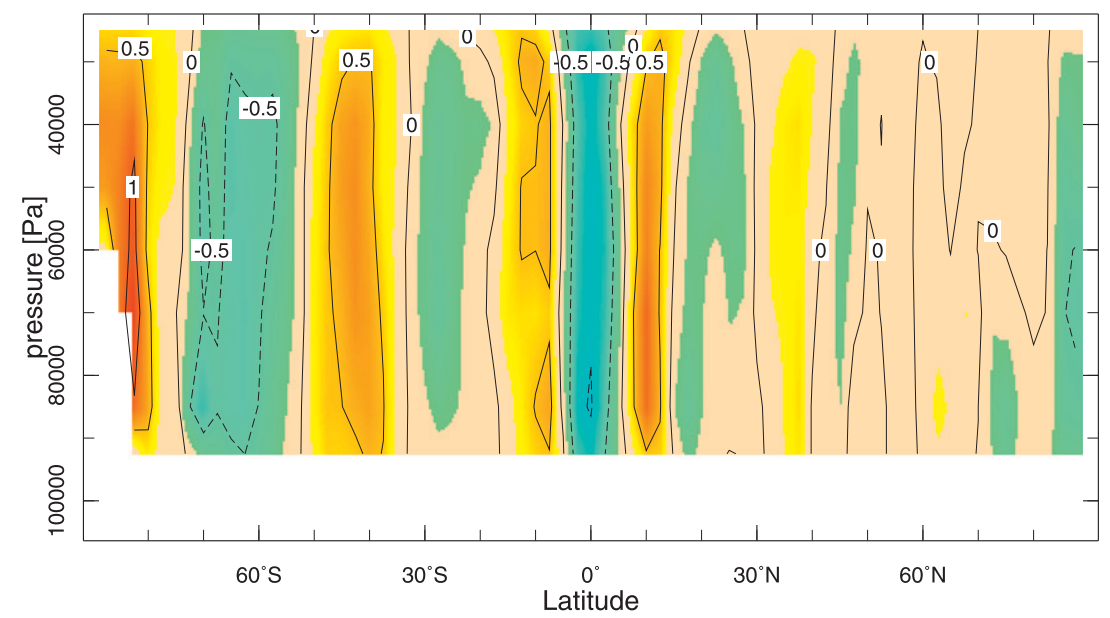

FIG. 12. As in Fig. 11, but for zonal mean vertical pressure velocity. Units are hPa day ${ }^{-1}$ change over the 1979-2008 period. 
the equator. The southern midlatitudes dipole is also present as in the 20CR. By this point in the evolution of anthropogenic-driven changes in mean circulation, the poleward expansion of the Hadley Cell, with a subsidence trend on the poleward flank of the subtropics, is not evident in the Northern Hemisphere. The trends in the 500-mb vertical velocity are shown in Fig. 13 (contours) together with the mean field (colors) and the zonal mean values. The total trend shows a clear La Niña-like pattern with ascending motion over the tropical west Pacific and Indian Oceans and descending motion over the eastern tropical Pacific Ocean. Once the ENSO influence is removed, there is reduced ascent in the west Pacific and Indian Ocean ascending branches of the Hadley and Walker Circulations and increased descent over the eastern equatorial Pacific. This is in agreement in sign, but not in amplitude, with the IPCC AR4/CMIP3 vertical velocity trends. Any evidence for the reduced subsidence in the subtropical branches of the Hadley Cell and a poleward expansion of these regions is subtle at best in both 20CR and the IPCC AR4/CMIP3 models but, in the zonal mean fields, there is some agreement in latitudinal pattern if not amplitude.

Figure 14 shows the $20 \mathrm{CR}$ trend, the residual trend after ENSO influences have been removed, and the IPCC AR4/CMIP3 multimodel mean trend in zonal mean zonal wind (contours) and temperature (colors). The total trend shows easterly anomalies in most of the tropics and westerly trends centered around $50^{\circ} \mathrm{N}$ and $50^{\circ} \mathrm{S}$, characteristic of La Niña situations (Seager et al. 2003). The tropical easterly trends, and much of the northern midlatitude tropospheric westerly trends, are removed when the influence of ENSO variability is removed. The residual trend has structural similarities to the multimodel mean trend but the exact latitudes where the various features appear are not matched. Thermal wind balance requires that the zonal mean zonal wind change be accompanied by a change in zonal mean meridional temperature gradients. The residual, ENSO influence-removed, temperature trend is quite similar to the total trend except for less Northern Hemisphere midlatitude warmth that was contributed to by the shift to a more La Niña-like state. The residual trend shows the upper tropical tropospheric warmth and low-level Arctic warmth characteristic of the IPCC AR4/CMIP3 radiatively forced temperature trend.

\section{Conclusions}

Climate models project significant changes in the distribution of $P-E$ as a consequence of rising GHGs, changes in trace gases, and global warming with already wet areas getting wetter, dry areas getting drier, and a poleward expansion of the subtropical dry zones, which suggests this change should have begun in the late twentieth century and that, in regions like southwest North America, grow to an amplitude equivalent to naturally occurring multiyear droughts by midcentury (Seager et al. 2007; Seager and Vecchi 2010). Given the serious consequences for water resources, agriculture, drought, and flood risk worldwide, it is important to determine if these model projections are correct and if this is already occurring. Here, we have attempted to do that by examining the moisture budget, and related circulation anomalies, in the model projections, the twentiethcentury reanalysis, and a model forced by the SST history. The methodology used draws a distinction between the mechanisms of naturally occurring $\bar{P}-\bar{E}$ variability and forced $\overline{\bar{P}}-\overline{\bar{E}}$ change and applies this to the historical record. The conclusions are as follows.

- There is a clear distinction between the mechanisms of the dominant mode of $\bar{P}-\bar{E}$ variability, which is ENSO, and the mechanisms of radiatively forced $\overline{\bar{P}}-\overline{\bar{E}}$ change. Natural variability of $\bar{P}-\bar{E}$ is "dynamically dominated" and created by circulation anomalies, ultimately forced by tropical SST and heating anomalies, working on the unchanged specific humidity field, while variations in specific humidity play little role. For example, widespread subtropical to midlatitude drying during $\mathrm{La}$ Niñas is associated with widespread descent. In contrast, the mechanisms of radiatively-forced $\overline{\bar{P}}-\overline{\bar{E}}$ change are about equally split between the thermodynamic and dynamic mechanisms and are hence "thermodynamics mediated." The thermodynamic term arises from intensified water vapor transports in a warmer, more moist atmosphere. Radiatively forced changes in the storm tracks and eddy moisture transports also cause subtropical drying and higher-latitude moistening.

- The dynamical component of the La Niña phase of natural variability of $\bar{P}-\bar{E}$ and forced change of $\overline{\bar{P}}-\overline{\bar{E}}$ are similar in that both have a poleward shift of the meridional circulation cells and storm track. However, they are dissimilar in the tropics with natural variability associated with a northward-shifted ITCZ and tropical tropospheric cooling. In contrast, radiatively forced change is associated with a weakening of the mean divergent circulation, increased ascent at the equator, and tropical tropospheric warming.

- The IPCC AR4/CMIP3-modeled thermodynamic, dynamic, and transient eddy contributions to natural $\bar{P}-\bar{E}$ variability are sufficiently similar to those diagnosed from the twentieth-century reanalysis that some confidence can be placed in the models' ability to represent these aspects of hydrological cycle variability.

- Two estimates of the post-1979 atmospheric state, the twentieth-century reanalysis, and an SST-forced atmospheric GCM are examined. After removing the 
20CR total trend

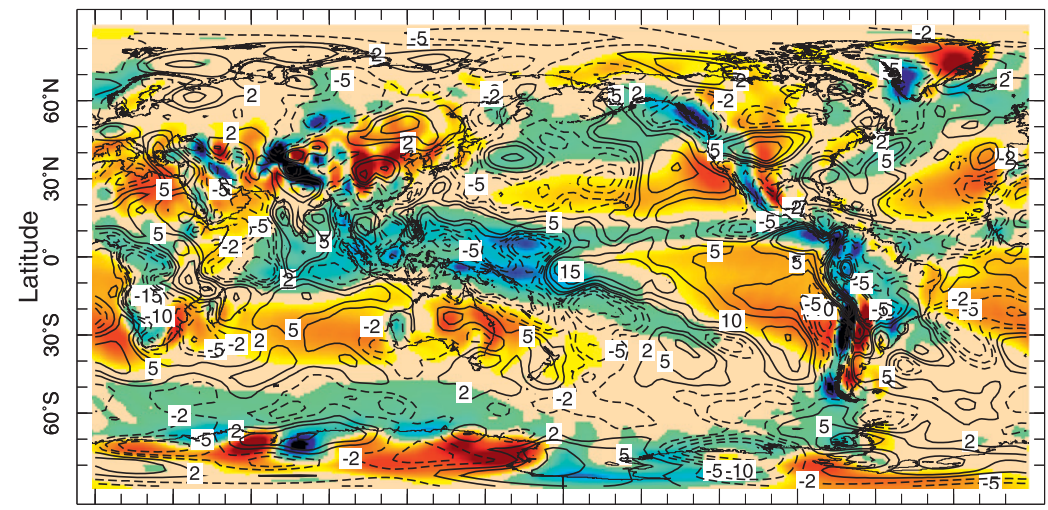

$0^{\circ} \quad 30^{\circ} \mathrm{E} \quad 60^{\circ} \mathrm{E} \quad 90^{\circ} \mathrm{E} \quad 120^{\circ} \mathrm{E} \quad 150^{\circ} \mathrm{E} \quad 180^{\circ} \quad 150^{\circ} \mathrm{W} \quad 120^{\circ} \mathrm{W} \quad 90^{\circ} \mathrm{W} \quad 60^{\circ} \mathrm{W} \quad 30^{\circ} \mathrm{W}$ Longitude

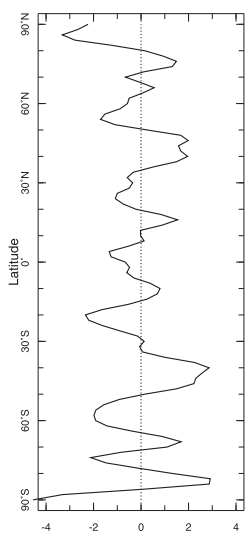

\section{CR trend in residual}
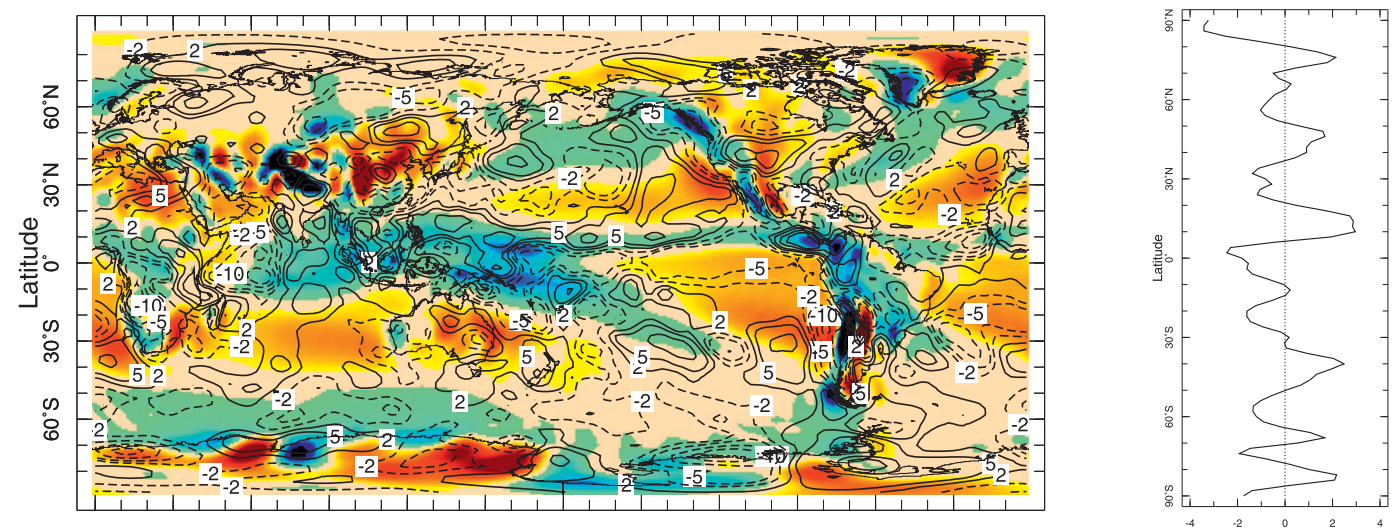

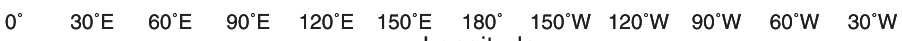
Longitude

\section{MMM trend}
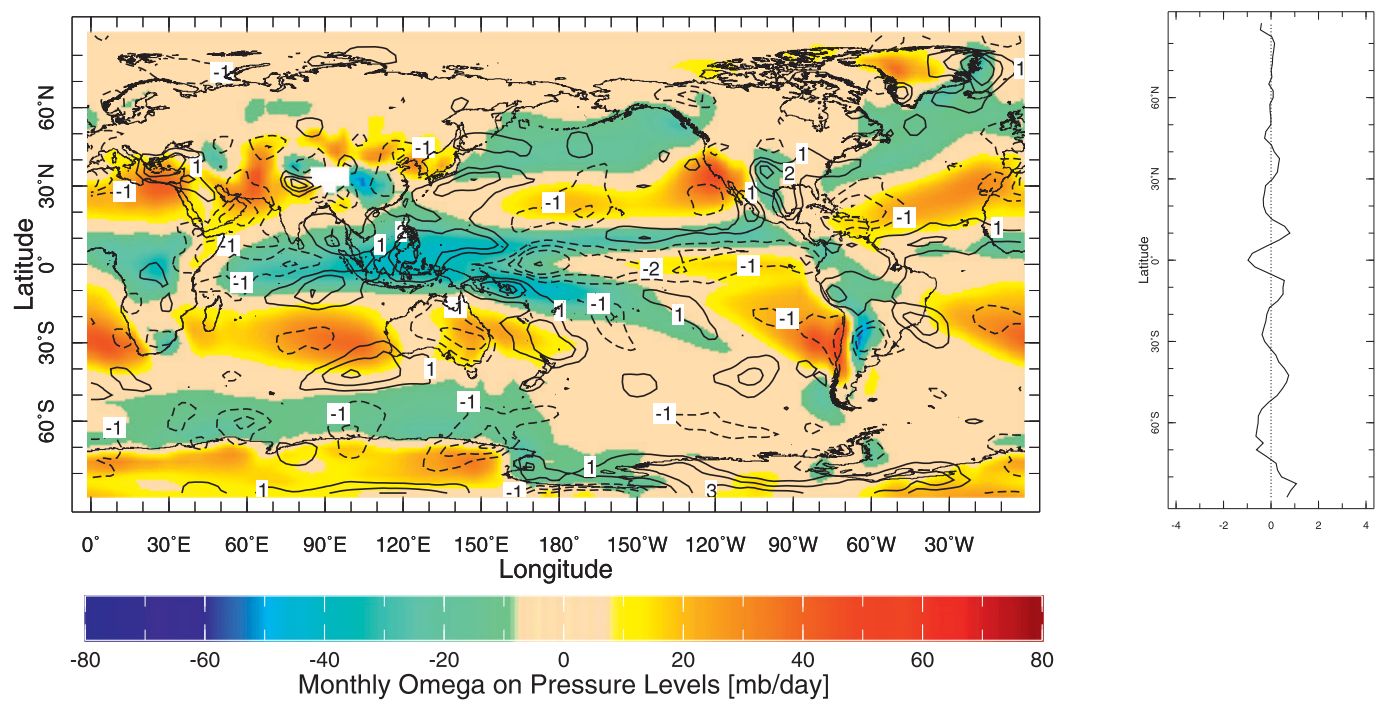

FIG. 13. As in Fig. 11, but for 500-hPa vertical pressure velocity trends (contours) and mean (color). (right) The zonal mean changes are shown. Units are hPa day ${ }^{-1}$ change over the 1979-2008 period. 


\section{CR total trend}

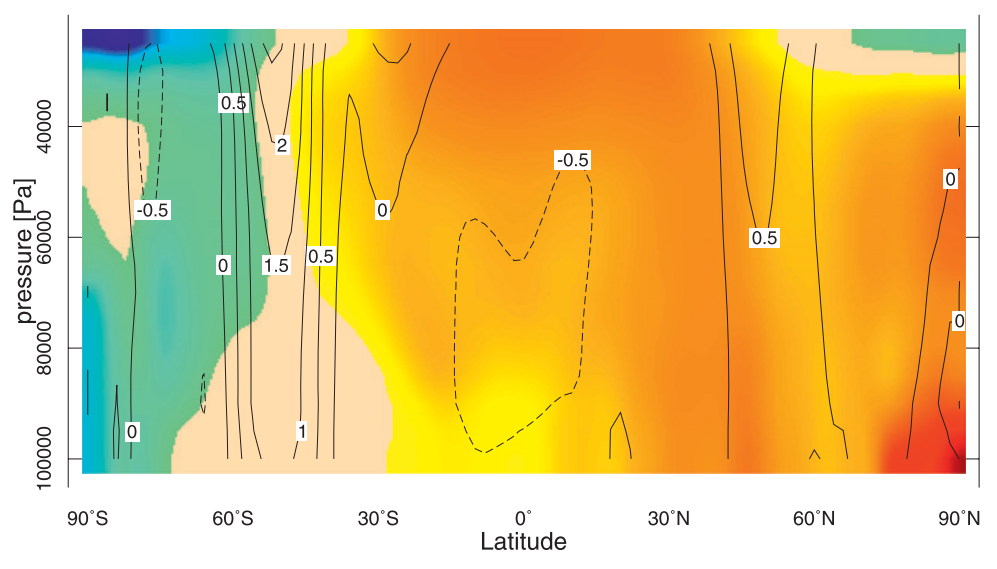

20CR trend in residual

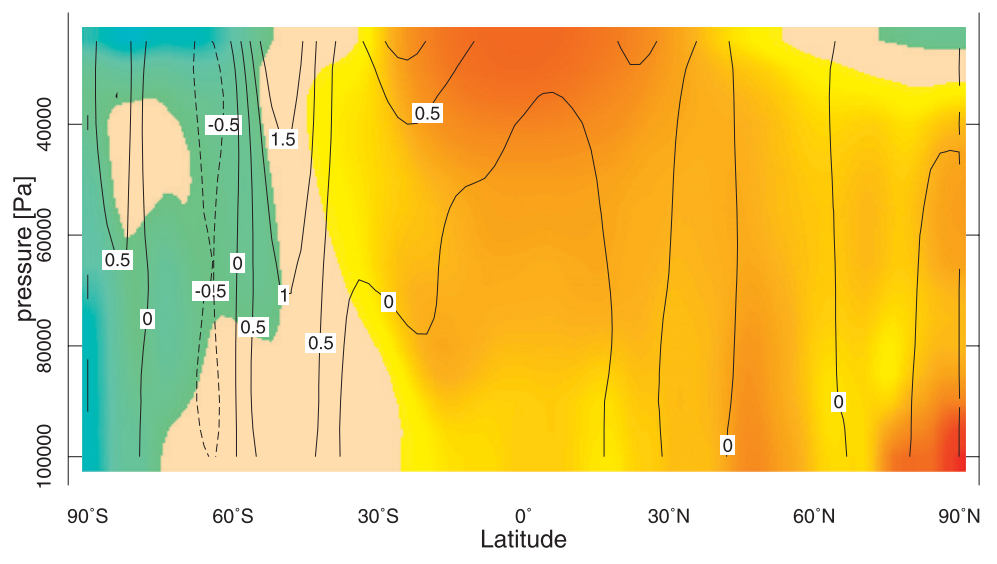

MMM trend

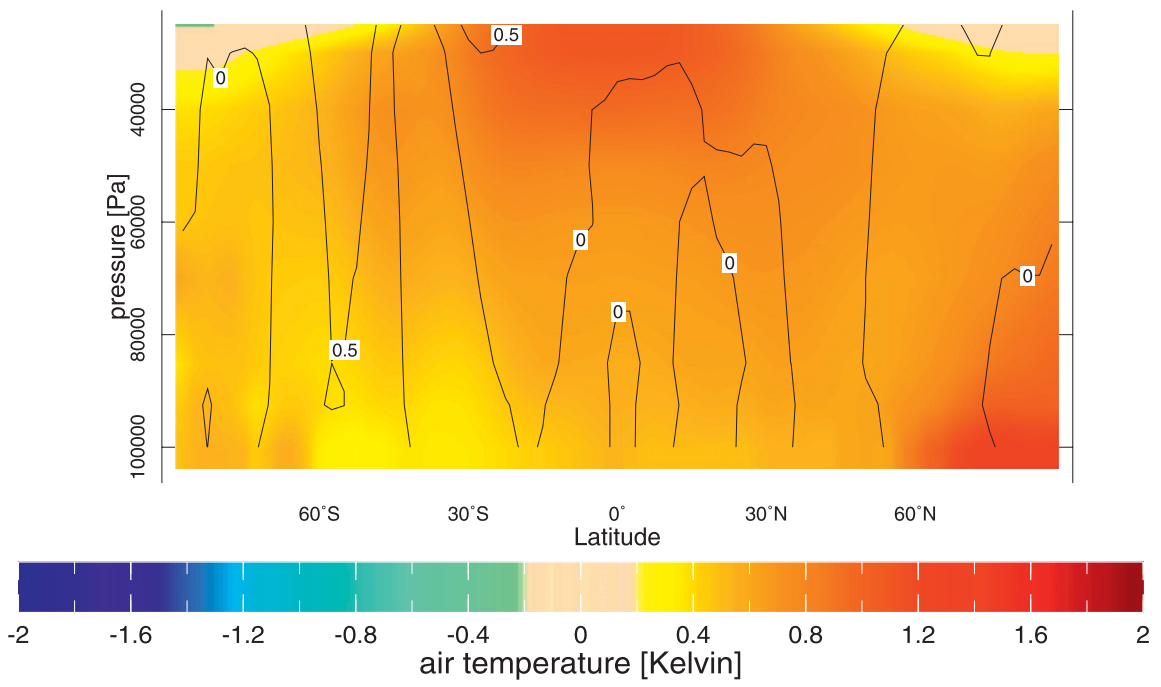

FIG. 14. As in Fig. 11, but for zonal mean temperature (color) and zonal velocity (contours). Velocity units are $\mathrm{m} \mathrm{s}^{-1}$ change over the 1979-2008 period. 
dominant modes of internal variability the trends in the residual moisture budget are examined. The total post1979 trends of $\bar{P}-\bar{E}$ show widespread subtropical drying but also a La Niña like shift in the tropics. The ENSO-removed trends, in contrast, show increased equatorial $\bar{P}-\bar{E}$ and subtropical decreases and higherlatitude moistening in the Southern Hemisphere. These trends are consistent in pattern and amplitude with the multimodel mean of the IPCC AR4/CMIP3 simulations of radiatively forced change over the past three decades, which includes the effects of $\mathrm{CO}_{2}$ increase, changes in $\mathrm{O}_{3}$, and other trace gases, solar irradiance etc.

- There is also some consistency in the mechanisms of post-1979 $\bar{P}-\bar{E}$ change between the estimates of the observed atmospheric state and the mean of the IPCC AR4/CMIP3 models. The thermodynamic term, a consequence of rising specific humidity and the unchanged circulation, causes increased $\bar{P}-\bar{E}$ near the equator and subtropical drying while the change in the mean circulation causes increased equatorial $\bar{P}-\bar{E}$ and drying in the northern tropics.

- The suggestion that anthropogenic changes in the hydrological cycle are underway is backed up by analysis of the trends in SST and estimated circulation. The total post-1979 trend is to more La Niña-like conditions but, once the part projecting onto patterns of internal variability has been removed, the residual shows equatorial Pacific warming in agreement with the IPCC AR4/CMIP3 models. Similarly, the residual vertical pressure velocity in the twentieth-century reanalysis has a weakening tropical divergent circulation as well as evidence of the changes in the Southern Hemisphere mean meridional circulation projected by the IPCC AR4/CMIP3 models. The presumed radiatively forced changes are more distinct in the tropics and Southern Hemisphere than in the Northern Hemisphere.

We have attempted to determine if anthropogenicinduced changes in the hydrological cycle are occurring, recognizing that the changes expected to date (on the basis of the IPCC AR4/CMIP3 model simulations) are small compared to the large-amplitude natural variations of the moisture budget on interannual to decadal time scales. Also, our methodology for separating between natural variability and forced change is subject to error. First, the identified modes of natural variability can be in error and incomplete. Second, it is possible that increased radiative forcing will cause shifts in the mean state that resemble the modes of natural variability confounding the attempt to separate these on the basis of spatial patterns or mechanisms. Indeed, we have argued that this can occur (Cane et al. 1997) and analysis of the entire period of instrumental records shows an increase, not decrease, in the zonal SST gradient across the equatorial Pacific (Karnauskas et al. 2009). Certainly more work is needed to address these sources of error and inconsistencies. However, by analyzing three-dimensional moisture budget fields and associated circulation fields, we do provide some suggestive evidence that the largescale hydroclimate changes anticipated as a consequence of changing trace gases - the wetting of the tropics and drying and poleward expansion of the dry subtropics and moistening further poleward-are actually underway raising confidence in model projections of the future. However, it must be noted that the "estimates of the observed atmospheric state" used fall considerably short of the quality of observational data that would be required to establish unambiguous conclusions. Despite recent developments in reanalyses this situation will remain so for the foreseeable future and continue to pose problems for efforts to detect anthropogenic climate change.

Acknowledgments. This work was supported by NOAA Grants NA08OAR4320912 and NA10OAR4320137 and NSF Grant ATM-08-04107. The comments and advice of the Global Decadal Hydroclimate (GloDecH) group at Lamont and Columbia were essential to the progress of this work. We thank three reviewers for constructive criticisms.

\section{REFERENCES}

Archer, C. L., and K. Caldeira, 2008: Historical trends in the jet streams. Geophys. Res. Lett., 35, L08803, doi:10.1029/ 2008GL033614.

Bjerknes, J., 1969: Atmospheric teleconnections from the equatorial Pacific. Mon. Wea. Rev., 97, 163-172.

Cane, M. A., A. C. Clement, A. Kaplan, Y. Kushnir, D. Pozdnyakov, R. Seager, S. E. Zebiak, and R. Murtugudde, 1997: Twentieth century sea surface temperature trends. Science, 275, 957-960.

Chou, C., and J. D. Neelin, 2004: Mechanisms of global warming impacts on regional tropical precipitation. J. Climate, 17, 2688-2701.

— - C C. Chen, and J. Tu, 2009: Evaluating the "rich-getricher" mechanism in tropical precipitation change under global warming. J. Climate, 22, 1982-2005.

Coelho, C. A. S., and L. Goddard, 2009: El Niño-induced tropical droughts in climate change projections. J. Climate, 22, 64566476.

Compo, G., and Coauthors, 2011: The twentieth century reanalysis project. Quart. J. Roy. Meteor. Soc., 137, 1-28.

Cook, B., R. Miller, and R. Seager, 2008: Dust and sea surface temperature forcing of the Dust Bowl drought. Geophys. Res. Lett., 35, L08710, doi:10.1029/2008GL033486.

- - , and - 2009: Amplification of the North American Dust Bowl drought through human-induced land degradation. Proc. Natl. Acad. Sci. USA, 106, 4997-5001. 
R. Seager, and R. Miller, 2011: Atmospheric circulation anomalies during two persistent North American droughts: 1932-39 and 1948-57. Climate Dyn., 36, 2339-2355.

Durack, P. J., and S. E. Wijffels, 2010: Fifty-year trends in global ocean salinities and their relationship to broad-scale warming. J. Climate, 23, 4342-4362.

Emori, S., and S. J. Brown, 2005: Dynamic and thermodynamic changes in mean and extreme precipitation under changed climate. Geophys. Res. Lett., 32, L17706, doi:10.1029/ 2005 GL023272.

Harnik, N., R. Seager, N. Naik, M. Cane, and M. Ting, 2011: The role of linear wave refraction in the transient eddy-mean flow response to tropical Pacific SST anomalies. Quart. J. Roy. Meteor. Soc., 136, 2132-2146.

Held, I. M., and B. J. Soden, 2006: Robust responses of the hydrological cycle to global warming. J. Climate, 19, 5686-5699.

Herweijer, C., R. Seager, and E. R. Cook, 2006: North American droughts of the mid to late nineteenth century: History, simulation and implications for Medieval drought. Holocene, 16, 159-171.

Hoerling, M. P., X.-W. Quan, and J. Eischeid, 2009: Distinct causes for two principal U.S. droughts of the 20th century. Geophys. Res. Lett., 36, L19708, doi:10.1029/2009GL039860.

— J. Jischeid, and J. Perlwitz, 2010: Regional precipitation trends: Distinguishing natural variability from anthropogenic forcing. J. Climate, 23, 2131-2145.

Huang, H., R. Seager, and Y. Kushnir, 2005: The 1976/77 transition in precipitation over the Americas and the influence of tropical SST. Climate Dyn., 24, 721-740.

Kang, S. M., L. M. Polvani, J. C. Fyfe, and M. Sigmond, 2011: Impact of polar ozone depletion on subtropical precipitation. Science, 332, 951-954.

Kaplan, A., M. A. Cane, Y. Kushnir, A. C. Clement, M. B. Blumenthal, and B. Rajagopalan, 1998: Analyses of global sea surface temperature: 1856-1991. J. Geophys. Res., 103,18 567-18 589.

Karnauskas, K. B., R. Seager, A. Kaplan, Y. Kushnir, and M. A. Cane, 2009: Observed strengthening of the zonal sea surface temperature gradient across the equatorial Pacific Ocean. J. Climate, 22, 4316-4321.

Kistler, R., and Coauthors, 2001: The NCEP-NCAR 50-Year Reanalysis: Monthly means CD-ROM and documentation. Bull. Amer. Meteor. Soc., 82, 247-268.

Liu, Z., S. Vavrus, F. He, N. Wen, and Y. Zhong, 2005: Rethinking tropical ocean response to global warming: The enhanced equatorial warming. J. Climate, 18, 4684-4700.

Lu, J., G. Vecchi, and T. Reichler, 2007: Expansion of the Hadley Cell under global warming. Geophys. Res. Lett., 34, 443, doi:10.1029/2006GL028443.

—, G. Chen, and D. M. W. Frierson, 2008: Response of the zonal mean atmospheric circulation to El Niño versus global warming. J. Climate, 21, 5835-5851.

— C. Deser, and T. Reichler, 2009: Cause of the widening of the tropical belt since 1958. Geophys. Res. Lett., 36, doi: 10.1029/ 2008 GL036 076.

Mariotto, A., N. Zeng, J.-H. Yoon, V. Artale, A. Navarra, P. Alpert, and L. Z. X. Li, 2009: Mediterranean water cycle changes: Transition to drier 21st century conditions in observations and CMIP3 simulations. Environ. Res. Lett., 3, doi:10.1088/17489326/3/4/044001.

Meehl, G., C. Covey, T. Delworth, M. Latif, B. McAvaney, J. F. B. Mitchell, R. J. Stouffer, and K. E. Taylor, 2007: The WCRP CMIP3 multimodel dataset: A new era in climate change research. Bull. Amer. Meteor. Soc., 88, 1383-1394.
Neelin, J. D., M. Munnich, H. Su, J. E. Meyerson, and C. E. Holloway, 2006: Tropical drying trends in global warming models and observations. Proc. Natl. Acad. Sci. USA, 103, 6110-6115.

Polvani, L. M., D. W. Waugh, G. J. P. Correa, and S. Son, 2011: Stratospheric ozone depletion: The main driver of 20th century atmospheric circulation changes in the southern hemisphere. J. Climate, 24, 795-812.

Previdi, M., and B. Liepert, 2007: Annular modes and Hadley Cell expansion under global warming. Geophys. Res. Lett., 34, L22701, doi:10.1029/2007GL031243.

Rayner, N., D. Parker, E. Horton, C. Folland, L. Alexander, D. Rowell, E. Kent, and A. Kaplan, 2003: Global analyses of sea surface temperature, sea ice, and night marine air temperature since the late nineteenth century. J. Geophys. Res., 108, 4407, doi:10.1029/2002JD002670.

Saha, S., and Coauthors, 2010: The NCEP Climate Forecast System Reanalysis. Bull. Amer. Meteor. Soc., 91, 1015-1057.

Schubert, S. D., M. J. Suarez, P. J. Pegion, R. D. Koster, and J. T. Bacmeister, 2004a: Causes of long-term drought in the United States Great Plains. J. Climate, 17, 485-503.

Dust Bowl. Science, 303, 1855-1859.

Seager, R., 2007: The turn-of-the-century North American drought: Dynamics, global context, and prior analogues. J. Climate, 20, 5527-5552.

_ , and G. A. Vecchi, 2010: Greenhouse warming and the 21st Century hydroclimate of the southwestern North America. Proc. Natl. Acad. Sci. USA, 107, $21277-21282$.

_ , N. Harnik, Y. Kushnir, W. Robinson, and J. Miller, 2003: Mechanisms of hemispherically symmetric climate variability. J. Climate, 16, 2960-2978.

,-- W. A. Robinson, Y. Kushnir, M. Ting, H. P. Huang, and J. Velez, 2005a: Mechanisms of ENSO-forcing of hemispherically symmetric precipitation variability. Quart. J. Roy. Meteor. Soc., 131, 1501-1527.

—, Y. Kushnir, C. Herweijer, N. Naik, and J. Velez, 2005b: Modeling of tropical forcing of persistent droughts and pluvials over western North America: 1856-2000. J. Climate, 18, 4068-4091.

—_, and Coauthors, 2007: Model projections of an imminent transition to a more arid climate in southwestern North America. Science, 316, 1181-1184.

_-, Y. Kushnir, M. Ting, M. A. Cane, N. Naik, and J. Velez, 2008: Would advance knowledge of 1930s SSTs have allowed prediction of the Dust Bowl drought? J. Climate, 21, 3261-3281.

—, and Coauthors, 2009: Mexican drought: An observational, modeling and tree ring study of variability and climate change. Atmósfera, 22, 1-31.

_ N. Naik, M. A. Cane, N. Harnik, M. Ting, and Y. Kushnir, 2010a: Adjustment of the atmospheric circulation to tropical Pacific SST anomalies: Variability of transient eddy propagation in the Pacific-North America sector. Quart. J. Roy. Meteor. Soc., 136, 277-296.

,$- \ldots$, and G. Vecchi, 2010b: Thermodynamic and dynamic mechanisms for large-scale changes in the hydrological cycle in response to global warming. J. Climate, 23, 4651-4668.

Seidel, D. J., Q. Fu, W. J. Randel, and T. J. Reichler, 2008: Widening of the tropical belt in a changing climate. Nat. Geosci., $\mathbf{1}$, 21-24.

Ting, M., Y. Kushnir, R. Seager, and C. Li, 2009: Forced and internal twentieth-century SST trends in the North Atlantic. J. Climate, 22, 1469-1481. 
Trenberth, K., G. Branstator, and P. Arkin, 1988: Origins of the 1988 North American drought. Science, 242, 1640-1645.

Vecchi, G. A., and B. J. Soden, 2007: Global warming and the weakening of the tropical circulation. J. Climate, 20, 43164340.

Wu, Y., M. Ting, R. Seager, H. Huang, and M. Cane, 2010: Changes in storm tracks and energy transports in a warmer climate simulated by the GFDL CM2.1 model. Climate Dyn., 37, 5372, doi:10.1007/s00382-010-0776-4.

, R. Seager, M. Ting, N. Naik, and T. Shaw, 2012: Atmospheric circulation response to an instantaneous doubling of carbon dioxide. Part I: Model experiments and transient thermal response in the troposphere. J. Climate, in press.

Yin, J. H., 2005: A consistent poleward shift of the storm tracks in simulations of 21 st century climate. Geophys. Res. Lett., 32, L18701, doi:10.1029/2005GL023684.

Zhang, R., F. W. Zwiers, G. C. Hegerl, F. H. Lambert, N. P. Gillett, S. Solomon, P. A. Stott, and T. Nozawa, 2008: Detection of human influence on twentieth-century precipitation trends. Nature, 448, 461-465, doi:10.1038/nature06025.

Zhang, Y., J. M. Wallace, and D. S. Battisti, 1997: ENSO-like decadeto-century scale variability: 1900-93. J. Climate, 10,1004-1020. 